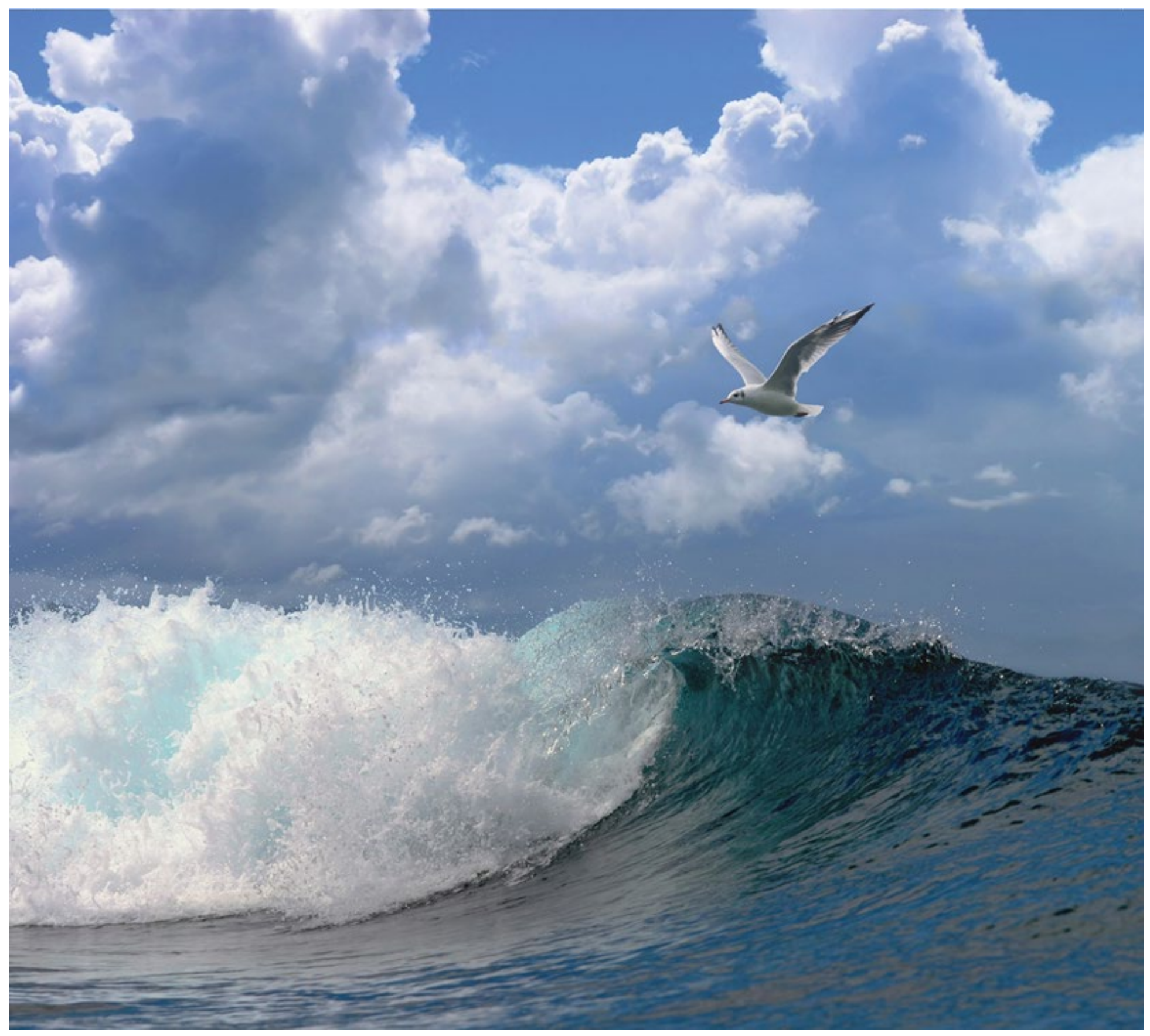

Gehalten organotin en effecten bij de Gewone Alikruik, de Gevlochten Fuikhoorn en de Purperslak langs de Nederlandse kust in 2017

Biologische gegevens van Mariene slak RWS-rapport BM 17.10 


\section{Gehalten organotin en effecten bij de Gewone Alikruik, de Gevlochten Fuikhoorn en de Purperslak langs de Nederlandse kust in 2017}

Biologische gegevens van Mariene slak

RWS-rapport BM 17.10

Auteur(s): $\quad$ A.C. Sneekes

Publicatiedatum: November 2018 
Sneekes A.C., 2018. Gehalten organotin en effecten bij de Gewone Alikruik, de Gevlochten Fuikhoorn en de Purperslak langs de Nederlandse kust in 2017. Biologische gegevens van Mariene slak. RWSrapport BM 17.10. Wageningen Marine Research Wageningen UR (University \& Research centre), Wageningen Marine Research rapport C058/18.

Keywords: Mariene slakken, Gewone Alikruik, Gevlochten Fuikhoorn, Purperslak, Intersex, Imposex

Opdrachtgever: Rijkswaterstaat

T.a.v.: M. Roos

Postbus 17

8200 AA Lelystad

Dit rapport is gratis te downloaden van https://doi.org/10.18174/457769

Wageningen Marine Research verstrekt geen gedrukte exemplaren van rapporten.

Wageningen Marine Research Wageningen UR is ISO 9001:2008 gecertificeerd.

(C) 2018 Wageningen Marine Research Wageningen UR

Wageningen Marine Research, onderdeel van Stichting Wageningen Research KvK nr. 09098104,

IMARES BTW nr. NL 8113.83.696.B16

Code BIC/SWIFT address: RABONL2U

IBAN code: NL 73 RABO 0373599285
De Directie van Wageningen Marine Research is niet aansprakelijk voor gevolgschade, noch voor schade welke voortvloeit uit toepassingen van de resultaten van werkzaamheden of andere gegevens verkregen van Wageningen Marine Research opdrachtgever vrijwaart Wageningen Marine Research van aanspraken van derden in verband met deze toepassing.

Dit rapport is vervaardigd op verzoek van de opdrachtgever hierboven aangegeven en is zijn eigendom. Niets uit dit rapport mag weergegeven en/of gepubliceerd worden, gefotokopieerd of op enige andere manier gebruikt worden zonder schriftelijke toestemming van de opdrachtgever. 


\section{Inhoud}

$\begin{array}{lr}\text { Samenvatting } & 4\end{array}$

$1 \quad$ Inleiding $\quad 5$

2 Kennisvraag $\quad 6$

3 Methoden $\quad 7$

$\begin{array}{lll}3.1 & \text { Bemonsteringslocaties } & 7\end{array}$

3.2 Intersex en imposex $\quad 8$

3.2.1 Gewone alikruiken $\quad 8$

3.2.2 Gevlochten fuikhoorns en purperslakken 9

3.3 Chemische analyses $\quad 9$

3.3.1 Droge stof 10

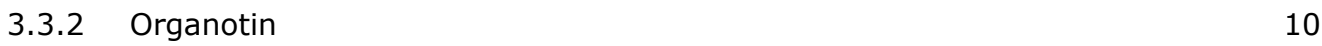

$\begin{array}{ll}3.4 & \text { Dataopslag en -registratie } \\ \end{array}$

4 Resultaten $r$

4.1 Intersex Gewone Alikruiken $\quad 11$

4.2 Imposex Gevlochten Fuikhoorns en Purperslakken $\quad 12$

$\begin{array}{ll}4.3 & \text { Chemische analyses } \\ \end{array}$

$5 \quad$ Kwaliteitsborging $r$

$\begin{array}{lr}\text { Literatuur } & 17\end{array}$

$\begin{array}{lr}\text { Verantwoording } & 18\end{array}$

Bijlagen rapport C058.18 Mariene slakken: $1.1 \mathrm{t} / \mathrm{m} 3.3 \quad 19$ 


\section{Samenvatting}

Sinds 2005 analyseert Wageningen Marine Research (WMR; voorheen IMARES) in opdracht van Rijkswaterstaat het voorkomen van intersex bij de Gewone Alikruiken (Littorina littorea) die op vaste locaties langs de Nederlandse kust verzameld worden. Het doel van dit onderzoek is effecten van verontreiniging met organotinverbindingen vast te stellen.

Gewone Alikruiken zijn in vergelijking met andere gastropoden echter vrij ongevoelig voor TBT. Bij de Gevlochten Fuikhoorn en de Purperslak resulteert TBT in imposex verschijnselen, een gevoeligere parameter dan intersex. Vanaf 2012 worden daarom naast de Gewone Alikruiken ook Gevlochten Fuikhoorns (Nassarius reticulatus) en Purperslakken (Nucella lapillus) verzameld. De Gevlochten Fuikhoorns zijn verzameld tijdens de schelpdierbemonsteringen die WMR in opdracht van het Ministerie van LNV uitvoert. Voor de Purperslakken is een aparte bemonstering, speciaal voor dit onderzoek, uitgevoerd.

Bij de Gewone Alikruik werden op geen van beide onderzochte locaties (Waddenzee kustzone Oost en West) intersex verschijnselen aangetroffen.

De Gevlochten Fuikhoorns, bemonsterd op de locaties Hollandse kustzone Noord, Midden en Zuid en de Haringvliet kustzone vertoonden op geen van de vier bemonsterde locaties verschijnselen van imposex.

Purperslakken werden bemonsterd op de locaties Grevelingen kustzone en op Oosterschelde en Westerschelde kustzone. Bij de Purperslak werd op de locatie Oosterschelde kustzone geen imposex geconstateerd. Op de locatie Grevelingen kustzone werd bij 2 van de 13 onderzochte vrouwtjes imposex geconstateerd beide in stadium 1c, resulterend in een VDSI van 0,13. In 2016 werd hier geen imposex geconstateerd, dit is dus een toename.

Op de locatie Westerschelde kustzone werd bij 2 van de 20 onderzochte vrouwtjes imposex geconstateerd ( 2 in stadium $1 a$ ), resulterend in een VDSI van 0,09. Dit is een afname in vergelijk met de voorgaande jaren (2016: 0,14; 2015: 0,50; 2014: 1,12 en 2013: 0,89).

Op basis van de imposex-resultaten bij de Gevlochten Fuikhoorn en de Purperslak, vallen dit jaar alle onderzochte monsters wederom in OSPAR Assessment Class A (VDSI Purperslak <0,3) of Class A/B (VDSI Gevlochten Fuikhoorn <0,3).

Van alle gemeten organotinverbindingen in de mariene slakken waren de gehalten aan tributyltin (TBT) het hoogst. De gehalten van TBT varieerde van $1,5 \mu \mathrm{g} \mathrm{Sn} / \mathrm{kg}$ (Haringvliet kustzone) tot $6,5 \mu \mathrm{g}$ $\mathrm{Sn} / \mathrm{kg}$ (Westerschelde kustzone). In 2017 waren de gehalten aan TBT het hoogst gemeten in de Purperslakken $(4,3 \mu \mathrm{g} \mathrm{Sn} / \mathrm{kg})$ en het laagste in de Gevlochten Fuikhoorn $(2,2 \mu \mathrm{g} \mathrm{Sn} / \mathrm{kg})$. 


\section{$1 \quad$ Inleiding}

Sinds 2005 analyseert Wageningen Marine Research (WMR, voorheen WMR) het voorkomen van intersex bij Gewone Alikruiken (Littorina littorea) die op vaste locaties langs de Nederlandse kust verzameld worden. Het doel van dit onderzoek is effecten van verontreiniging met organotinverbindingen, specifiek tributyltinverbindingen (TBT), vast te stellen.

De uitvoering geschiedde volgens het Projectplan chemisch meetnet MWTL 2015; "Monitoren van organotinverbindingen en biologische effecten in mariene slak 2015", auteur M.H. van der Weijden, van 27 oktober 2014 (dit projectplan is op 15 juli 2015 verstrekt).

Gewone Alikruiken zijn algengrazers en in vergelijking met andere gastropoden vrij ongevoelig voor TBT. Blootstelling aan TBT kan leiden tot intersex, een afwijking waarbij de vrouwelijke genitaliën vergroeien tot mannelijke genitaliën. Deze vrouwtjes zijn al volledig steriel vanaf stadium 2 (Oehlmann et al., 1996). Bij roofslakken resulteert blootstelling aan TBT in imposex. Hierbij ontwikkelen de vrouwtjes naast normale vrouwelijke genitaliën, ook mannelijke genitaliën, die uiteindelijk de oviduct (eileider) blokkeren, wat leidt tot steriliteit (en sterfte) in stadium 5 en 6 (Bauer et al., 1995). Imposex treedt al bij veel lagere TBT-gehalten op dan intersex.

De Purperslak (Nucella lapillus) is een van de gevoeligste soorten met betrekking tot TBT. Deze soort komt voor in de Zeeuwse wateren en vertoont voldoende variatie in imposex om een realistisch onderscheid te kunnen maken tussen locaties met betrekking tot de TBT-belasting (Kaag \& Jol, 2007). Door de beperkte verspreiding is deze soort echter niet geschikt om als indicatorsoort voor de gehele Nederlandse kustzone te dienen.

Een alternatief is de Gevlochten Fuikhoorn (Nassarius reticulatus). Deze soort wordt sinds enkele jaren regelmatig aangetroffen tijdens de jaarlijkse schelpdiersurveys die WMR in opdracht van het Ministerie van EZ uitvoert in de Nederlandse wateren. Ook de Gevlochten Fuikhoorn vertoont imposex en is gevoeliger dan de Gewone Alikruik, maar niet zo extreem gevoelig als de Purperslak (Stroben et al., 1992; Bryan et al., 1993; Oehlmann et al., 1996). Vanaf 2009 zijn daarom niet alleen Gewone Alikruiken verzameld op de standaardlocaties, maar zijn ook op vijf locaties Gevlochten Fuikhoorns verzameld (Kaag et al., 2009). De keuze van de locaties was van tevoren alleen globaal bepaald (monding Westerschelde, monding Europoort en voor de kust van Noord-Holland), aangezien niet bekend was waar de aantallen hoog genoeg zouden zijn voor het verzamelen van een voldoende groot monster. Tijdens de bemonsteringen vanaf 2011 is naast de Gewone Alikruik en de Gevlochten Fuikhoorn, tevens de Purperslak als indicatorsoort bemonsterd en is de Nederlandse kustzone ingedeeld in bemonsteringsgebieden. Hierdoor kunnen binnen een gebied kleine monsters van een soort samengevoegd worden. 


\section{Kennisvraag}

In het kader van de hierboven genoemde opdracht werden door Wageningen Marine Research de volgende werkzaamheden uitgevoerd:

- $\quad$ Plannen van het onderzoek

- $\quad$ Verzamelen van mariene slakken in negen verschillende bemonsteringsgebieden

- $\quad$ Karakteriseren mariene slakken en beoordelen staat van intersex/imposex

- $\quad$ Het uitvoeren van chemische analyses

- $\quad$ Het rapporteren van de verkregen resultaten

- $\quad$ Het genereren van DONAR-files 


\section{Methoden}

\subsection{Bemonsteringslocaties}

Voor de bemonstering van slakken heeft RWS in totaal negen aandachtsgebieden gedefinieerd (Tabel 1). In elk aandachtsgebied wordt één monster geanalyseerd.

\section{Tabel 1 Voorgestelde onderzoeklocaties waar de verschillende geplande indicatorsoorten volgens het projectplan uit 2015 bemonsterd dienen te worden}

\begin{tabular}{|llll|}
\hline Gebied & DONAR-code & Locatie & Geplande soort \\
\hline Waddenzee kustzone Oost & WADDZKZNOT & Eems-Dollard/Eemshaven & Gewone Alikruik \\
Waddenzee kustzone West & WADDZKZNWT & Waddenzee-West/Roptazijl & Gewone Alikruik \\
Hollandse kustzone Noord & HOLLSKZNND & Petten/Den Helder & Gevlochten Fuikhoorn \\
Hollandse kustzone Midden & HOLLSKZNMDN & Monding Noordzeekanaal & Gevlochten Fuikhoorn \\
Hollandse kustzone Zuid & HOLLSKZNZD & Scheveningen & Gevlochten Fuikhoorn \\
Haringvliet kustzone & HARVKZNE & Monding Haringvliet & Gevlochten Fuikhoorn \\
Grevelingen kustzone & GREVLGKZNE & Monding Grevelingen & Purperslak \\
Oosterschelde kustzone & OOSTSDKZNE & Monding Oosterschelde & Purperslak \\
Westerschelde kustzone & WESTSDKZNE & Monding Westerschelde & Purperslak \\
\hline
\end{tabular}

In Figuur 1 zijn de onderzoeklocaties met hun bijbehorende DONAR-codes voor 2017 weergegeven die door de opdrachtgever in het projectplan zijn voorgesteld.

Bij de Gewone Alikruiken wordt de mate van intersex vastgesteld en wordt het organotin-gehalte in het weefsel van de dieren bepaald. Bij de Gevlochten Fuikhoorns en de Purperslakken wordt de mate van imposex vastgesteld en wordt eveneens het organotin-gehalte in het weefsel van de dieren bepaald. 


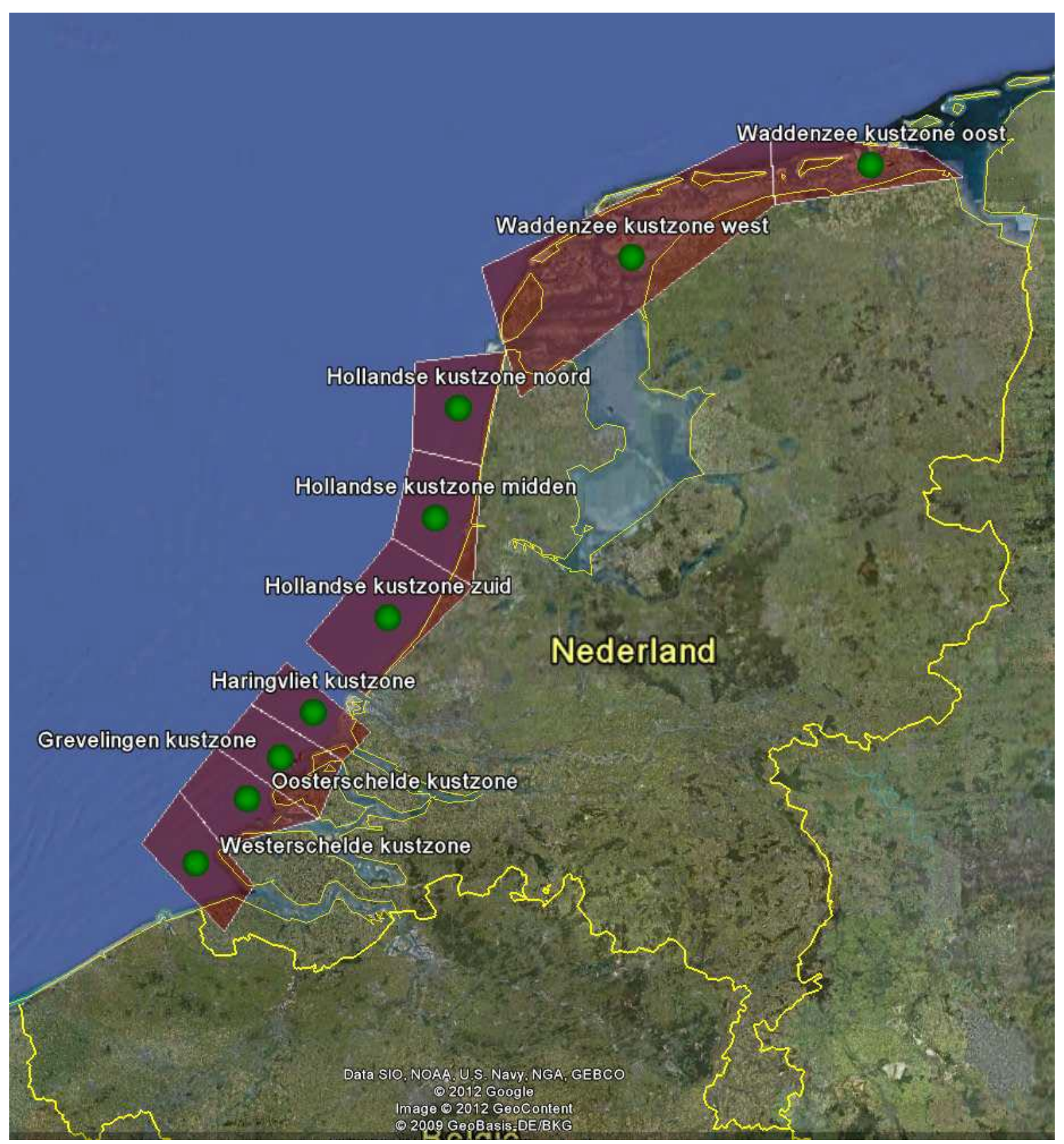

Figuur 1 Voorgestelde onderzoeklocaties in 2017 (uit Projectplan RWS 2015). De paarse vlakken geven de grenzen van de gebieden aan waarbinnen de slakken worden gezocht, de groene stippen het zwaartepunt van de locaties.

\subsection{Intersex en imposex}

\subsubsection{Gewone alikruiken}

Gewone Alikruiken werden op 16 maart 2017 verzameld, door handmatig op de dijk te rapen bij laag water, op twee Waddenzee locaties (Tabel 3). Op beide locaties zijn voldoende Gewone Alikruiken geraapt voor de analyse van exact 40 individuen (exact 40 exemplaren volgens richtlijn OSPAR en Projectplan 2015) op het voorkomen van intersex en op gehalten organotin-verbindingen in de weefsels. De verzamelde Gewone Alikruiken zijn dezelfde dag gekoeld (koelbox met voldoende koelelementen) naar het laboratorium in Yerseke vervoerd. 
De intersex analyse is uitgevoerd conform Jol (2004) en OSPAR (2008). Intersex bij vrouwelijke Gewone Alikruiken kan in een gradueel systeem geclassificeerd worden, waarbij vijf stadia worden onderscheiden, lopend van 0 (geen effect) tot 4 (volledig steriliteit).

De ISI (intersex index) is het gemiddelde intersex stadium van de populatie. De ISI wordt als volgt bepaald:

ISI = som intersex stadia alle vrouwtjes/aantal vrouwtjes

\subsubsection{Gevlochten fuikhoorns en purperslakken}

Gevlochten Fuikhoorns zijn tussen 29 maart en 18 april verzameld tijdens de WOTschelpdierbemonstering (Tabel 3). Tijdens deze bemonstering worden de schelpdieren bemonsterd met de WMR-bodemschaaf in raaien van 150 meter lang. De schaaf is $15 \mathrm{~cm}$ breed, zodat een totaal oppervlak van $22,5 \mathrm{~m}^{2}$ wordt bemonsterd. Exact 40 exemplaren Gevlochten Fuikhoorns werden zo mogelijk nog dezelfde dag aan boord van het schip geanalyseerd.

Op 13 maart 2017 werden Purperslakken verzameld tijdens een aparte bemonstering speciaal voor dit project (Tabel 4). Purperslakken bevinden zich in het intertijdegebied en worden bij laag water handmatig van de stenen geraapt. Exact 40 exemplaren zijn onderzocht.

De imposex-analyse in beide organismen is uitgevoerd conform Jol (2007) en OSPAR (2008). Imposex bij vrouwelijke Gevlochten Fuikhoorns en Purperslakken kan in een gradueel systeem geclassificeerd worden, lopend van 0 (geen effect) tot 4 (Gevlochten Fuikhoorn) of 6 (Purperslak). Er zijn geen aanwijzingen dat bij de Gevlochten Fuikhoorn steriliteit optreedt (stadia 5 en 6).

De belangrijkste karakteristiek voor de populatie is de VDSI (Vas Deferens Sequence Index). Dit is het gemiddelde imposex stadium in de populatie. De VDSI wordt als volgt bepaald:

VDSI $=\frac{\left.\sum \text { (imposex stadia van alle vrouwtjes }\right)}{\text { totaal aantal vrouwtjes }}$

Daarnaast kan ook de Relative Penis Size worden uitgedrukt in een index (RPSI). De RPSI wordt als volgt bepaald:

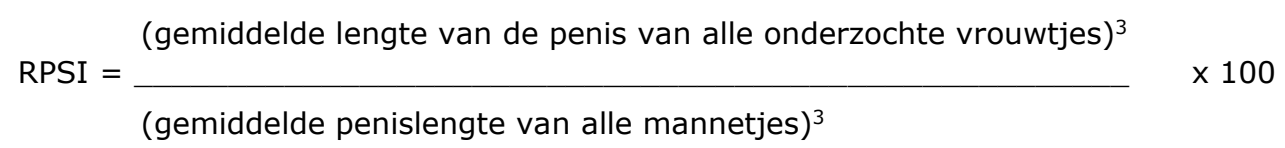

Alle onderzochte dieren zijn voorbehandeld voor de analyse op organotinverbindingen. Deze voorbehandeling bestaat uit het zoveel mogelijk verwijderen van de schaal en operculum (afsluiting mondopening), schoonspoelen en invriezen. De ingevroren monsters zijn naar het laboratorium van WMR in IJmuiden gebracht voor analyse van de gehalten organotin.

\subsection{Chemische analyses}

Voor elke onderzochte locatie is van de weefsels van alle op intersex en imposex onderzochte slakken een mengmonster gemaakt t.b.v. chemische analyses. De chemische componenten die in de monitoringscyclus van 2017 zijn geanalyseerd en gerapporteerd zijn opgenomen in Tabel 3. De organotin gehalten zijn geanalyseerd en gerapporteerd als gehalte $\mathrm{Sn}$ en kation. 


\begin{tabular}{|l|l|l|l|}
\hline Component & Rapport & Donar-code & CAS-nummer \\
\hline & & & \\
\hline Percentage droge stof & Droge stof \% & $\%$ DS & n.v.t. \\
\hline Monobutyltin & MBT & MC4ySn & $78763-54-9$ \\
\hline Dibutyltin & DBT & DC4ySn & $1002-53-5$ \\
\hline Tributyltin & TBT & TC4ySn & $688-73-3$ \\
\hline Monofenyltin & MPhT & MFySn & $2406-68-0$ \\
\hline Difenyltin & DPhT & DFySn & $1011-95-6$ \\
\hline Trifenyltin & TPhT & TFySn & $668-34-8$ \\
\hline
\end{tabular}

In paragraaf 3.3.1 t/m 3.3.2 wordt een korte beschrijving en een verwijzing naar de Interne Standaard Werkvoorschriften (ISW's) gegeven die gebruikt zijn voor de uitvoering van de chemische analyses.

\subsubsection{Droge stof}

Voor de bepaling van het droge stofgehalte werd het gewogen monster gemengd met een oppervlakte vergrotende stof, vervolgens gedroogd in een stoof $\left(105^{\circ} \mathrm{C}, 3 \mathrm{uur}\right)$ en na afkoelen in een exsiccator teruggewogen.

De methode is vastgelegd in IMARES ISW 2.10.3.011 Dierlijk weefsel. "Bepalen van het gehalte aan vocht; gravimetrie" en is geaccrediteerd door de Raad voor Accreditatie (testlaboratoriumnummer L097, verrichting nummer 2).

\subsubsection{Organotin}

Ionogene organotinverbindingen kwamen via een schudextractie met methanol, azijnzuur en hexaan beschikbaar voor alkylering. Vervolgens werden de alkyltinverbindingen geëthyleerd met natriumtetraethylboraat. Na een clean-up met aluminiumoxide werden de extracten geanalyseerd met behulp van GC-MS (SIM mode). Zes organotinverbindingen worden vervolgens gerapporteerd (MBT, DBT, TBT, MPhT, DPhT en TPhT) als Sn en als kation.

De methode is vastgelegd in IMARES ISW 2.10.3.024 Dierlijk weefsel. "Bepalen van het gehalte aan organotinverbindingen na extractie en derivatisatie; GC-EI-MS" en is geaccrediteerd door de Raad van Accreditatie (testlaboratoriumnummer L097, verrichting nummer 18).

\subsection{Dataopslag en -registratie}

De gegenereerde data werden opgeslagen in LIMS. Een DONAR-script is beschikbaar dat ervoor zorgt dat de gegevens uit LIMS op de juiste manier in een DONAR-file terecht komen. De analyseresultaten uit het meetrapport die in LIMS zijn geïmporteerd, werden gecontroleerd door een andere analist die bevoegd is voor de uitvoering van betreffende bepaling dan de uitvoerend analist. De Exceltabellen die uit LIMS zijn gegenereerd en in het rapport zijn opgenomen, werden door de uitvoerende analisten gecontroleerd op eventuele fouten en geparafeerd voor vrijgave. Van elk analyseresultaat is beoordeeld of het voldoet aan de kwaliteitscriteria die zijn genoemd in het betreffende ISW, indien dit niet het geval was is de reden daarvan in het rapport vermeld. 


\section{Resultaten}

De resultaten vermeld in dit rapport zijn alleen van toepassing op de geanalyseerde monsters.

In onderstaande tabellen zijn de posities aangegeven waar in 2017 Gewone Alikruiken (Tabel 3), Gevlochten Fuikhoorns (Tabel 4) en Purperslakken (Tabel 5) bemonsterd zijn. Deze posities betreffen het zwaartepunt van de door RWS in het Projectplan opgegeven hoekpunten voor één locatie.

Binnen één locatie kunnen op meerdere plekken slakken bemonsterd zijn en samengevoegd tot één mengmonster. Tevens zijn de bemonsterdata, locatienamen en de bijbehorende DONAR-locatiecodes weergegeven.

Tabel 3 Datum van bemonstering Gewone Alikruiken en posities in de monstergebieden.

\begin{tabular}{|lllll|}
\hline Datum & Gebied & DONAR-code & \multicolumn{2}{c|}{ Coördinaten conform DONAR } \\
& & & $\mathbf{X}$ & $\mathbf{Y}$ \\
\hline $16 / 03 / 2017$ & Waddenzee kustzone Oost & WADDZKZNOT & 006283283 & 053290758 \\
$16 / 03 / 2017$ & Waddenzee kustzone West & WADDZKZNWT & 005195792 & 053134560 \\
\hline
\end{tabular}

Tabel 4 Datum van bemonstering Gevlochten Fuikhoorns en posities in de monstergebieden.

\begin{tabular}{|lllll|}
\hline Datum & Gebied & DONAR-code & \multicolumn{2}{l|}{ Coördinaten conform DONAR } \\
& & & X & Y \\
\hline $18 / 04 / 2017$ & Hollandse kustzone Noord & HOLLSKZNND & 004311444 & 052480536 \\
$29 / 03 / 2017$ & Hollandse kustzone Midden & HOLLSKZNMDN & 004250100 & 052292709 \\
$10 / 04 / 2017$ & Hollandse kustzone Zuid & HOLLSKZNZD & 004120880 & 052122995 \\
$12 / 04 / 2017$ & Haringvliet kustzone & HARVKZNE & 003515590 & 051561495 \\
\hline
\end{tabular}

Tabel 5 Datum van bemonstering Purperslakken en posities in de monstergebieden.

\begin{tabular}{|lllll|}
\hline Datum & Gebied & DONAR-code & \multicolumn{2}{l|}{ Coördinaten conform DONAR } \\
& & & $\mathbf{X}$ & $\mathbf{Y}$ \\
\hline $13 / 03 / 2017$ & Grevelingen kustzone & GREVLGKZNE & 003430300 & 051482900 \\
$13 / 03 / 2017$ & Oosterschelde kustzone & OOSTSDKZNE & 003341009 & 051412330 \\
$13 / 03 / 2017$ & Westerschelde kustzone & WESTSDKZNE & 003202679 & 051301316 \\
\hline
\end{tabular}

De resultaten van alle afzonderlijke monsters worden zowel in dit rapport als in de DIF t.b.v. ICES gerapporteerd.

\subsection{Intersex Gewone Alikruiken}

In Bijlage 1.1 \& 1.2 zijn de volledige resultaten weergegeven van de intersex analyse in de Gewone Alikruiken, in Tabel 6 zijn de resultaten voor intersex samengevat. Ongeveer de helft van de onderzochte exemplaren bestond uit vrouwtjes.

In 2017 werd geen intersex waargenomen in de geanalyseerde Gewone Alikruiken. 


\begin{tabular}{|l|l|l|l|}
\hline Gebied & Soort & $\begin{array}{l}\text { Aantal vrouwtjes } \\
\text { (met intersex) }\end{array}$ & ISI \\
\hline Waddenzee kustzone Oost & Gewone Alikruik & $20(0)$ & $\mathrm{nb}$ \\
\hline Waddenzee kustzone West & Gewone Alikruik & $18(0)$ & $\mathrm{nb}$ \\
\hline
\end{tabular}

\subsection{Imposex Gevlochten Fuikhoorns en Purperslakken}

In Bijlage $2.1 \mathrm{t} / \mathrm{m} 2.3$ zijn de volledige resultaten weergegeven van de imposex analyse van Gevlochten Fuikhoorns en Purperslakken, in Tabel 7 zijn de resultaten voor imposex samengevat. Van het totale aantal slakken onderzocht op imposex bestond de helft uit vrouwtjes, waarbij het laagste aantal vrouwtjes werden aangetroffen in de Grevelingen kustzone (13 stuks) en de hoogste aantal in de Hollandse kustzone Midden (26 stuks).

Bij de Gevlochten Fuikhoorns werden op geen van de vier bemonsterde locaties vrouwtjes met verschijnselen van imposex aangetroffen.

Bij de Purperslak werd op de locatie Oosterschelde kustzone geen imposex geconstateerd. Op de locatie Grevelingen kustzone werd bij 2 van de 13 onderzochte vrouwtjes imposex geconstateerd beide in stadium 1c, resulterend in een VDSI van 0,13. In 2016 werd hier geen imposex geconstateerd en is dus een toename (Kotterman et. al., 2016).

Op de locatie Westerschelde kustzone werd bij 2 van de 20 onderzochte vrouwtjes imposex geconstateerd ( 2 in stadium $1 \mathrm{a}$ ), resulterend in een VDSI van 0,09. Dit is een afname in vergelijk met de voorgaande jaren waarbij 2016: 0,14; 2015: 0,50; 2014: 1,12 en 2013: 0,89 (Kotterman et. al., 2016, Hoek et. al., 2015, 2014, 2013).

\section{Tabel 7 Resultaten imposex analyse 2017.}

\begin{tabular}{|l|l|l|l|l|l|}
\hline Locatie & Soort & $\begin{array}{l}\text { Aantal } \\
\text { vrouwtjes } \\
\text { (met imposex) }\end{array}$ & $\begin{array}{l}\text { Aantal } \\
\text { (Stadium) }\end{array}$ & VDSI & RPSI \\
\hline Hollandse kustzone Noord & Gevlochten Fuikhoorn & $21(0)$ & $21(0)$ & $\mathrm{nb}$ & $\mathrm{nb}$ \\
\hline $\begin{array}{l}\text { Hollandse kustzone } \\
\text { Midden }\end{array}$ & Gevlochten Fuikhoorn & $26(0)$ & $26(0)$ & $\mathrm{nb}$ & $\mathrm{nb}$ \\
\hline Hollandse kustzone Zuid & Gevlochten Fuikhoorn & $21(0)$ & $21(0)$ & $\mathrm{nb}$ & $\mathrm{nb}$ \\
\hline Haringvliet kustzone & Gevlochten Fuikhoorn & $16(0)$ & $16(0)$ & $\mathrm{nb}$ & $\mathrm{nb}$ \\
\hline Grevelingen kustzone & Purperslak & $13(2)$ & $11(0), 2(1 \mathrm{c})$ & 0,13 & 0,000000 \\
\hline Oosterschelde kustzone & Purperslak & $23(0)$ & $23(0)$ & $\mathrm{nb}$ & $\mathrm{nb}$ \\
\hline Westerschelde kustzone & Purperslak & $20(2)$ & $\begin{array}{l}18(0), 2 \\
(1 \mathrm{a})\end{array}$ & 0,09 & 0,000181 \\
\hline
\end{tabular}

\subsection{Chemische analyses}

De analyses van de organotinverbindingen en van droge stof zijn in augustus 2017 uitgevoerd in het laboratorium van WMR-locatie IJmuiden. Hiervoor werden de LIMS-request nummers en monstercodes gebruikt voor de verschillende gebieden zoals weergegeven in Tabel 8. 
Tabel 8 Gebruikte LIMS-request nummers en monstercodes voor de chemische analyses in Mariene slakken 2017.

\begin{tabular}{|l|l|l|l|}
\hline Gebied & Monstersoort & $\begin{array}{l}\text { LIMS-request } \\
\text { nummer }\end{array}$ & Monstercode \\
\hline Waddenzee kustzone Oost & Alikruik & RQ20170209/004 & $2017 / 0023$ \\
\hline Waddenzee kustzone West & Alikruik & RQ20170209/005 & $2017 / 0064$ \\
\hline Hollandse kustzone Noord & Gevlochten Fuikhoorn & RQ20170209/006 & $2017 / 0105$ \\
\hline Hollandse kustzone Midden & Gevlochten Fuikhoorn & RQ20170209/007 & $2017 / 0146$ \\
\hline Hollandse kustzone Zuid & Gevlochten Fuikhoorn & RQ20170209/008 & $2017 / 0187$ \\
\hline Haringvliet kustzone & Gevlochten Fuikhoorn & RQ20170209/009 & $2017 / 0228$ \\
\hline Grevelingen kustzone & Purperslak & RQ20170209/010 & $2017 / 0269$ \\
\hline Oosterschelde kustzone & Purperslak & RQ20170209/011 & $2017 / 0310$ \\
\hline Westerschelde kustzone & Purperslak & RQ20170209/012 & $2017 / 0351$ \\
\hline
\end{tabular}

In Tabel 9 en Tabel 10 zijn de resultaten van de organotinverbindingen en gehalten aan droge stof weergegeven. Van alle gemeten organotinverbindingen in de mariene slakken waren de gehalten aan tributyltin (TBT) het hoogst. De gehalten van TBT varieerde van $1,5 \mu \mathrm{g} \mathrm{Sn} / \mathrm{kg}$ (Haringvliet kustzone) tot $6,5 \mu \mathrm{g} \mathrm{Sn} / \mathrm{kg}$ (Westerschelde kustzone) wat overeenkomt met een gehalte aan TBT-kation van 3.8 $\mu \mathrm{g}$ kation/kg (Haringvliet kustzone) tot $16 \mu \mathrm{g}$ kation/kg (Westerschelde kustzone). In 2017 waren de gehalten aan TBT het hoogst gemeten in de Purperslakken (gemiddeld 4,3 $\mu \mathrm{g} \mathrm{Sn} / \mathrm{kg}$ ) en het laagste in de Gevlochten Fuikhoorn (gemiddeld 2,2 $\mu \mathrm{g} \mathrm{Sn} / \mathrm{kg}$ ).

Tabel 9 Overzicht van de resultaten van de organotin gehalten uitgedrukt als Tin en het gehalte aan droge stof in mariene slakken 2017.

\begin{tabular}{|c|c|c|c|c|c|c|c|c|}
\hline \multirow[t]{2}{*}{ Monstercode } & \multirow[t]{2}{*}{ Gebied } & \multicolumn{6}{|c|}{ Resultaten Organotin ( $\mu \mathrm{g} \mathrm{Sn/kg)}$} & \multirow{2}{*}{$\begin{array}{l}\text { Droge } \\
\text { stof } \\
(\%)\end{array}$} \\
\hline & & MBT & DBT & TBT & MPhT & DPhT & TPhT & \\
\hline & & & $\mathbf{Q}$ & $\mathbf{Q}$ & & & & $\mathbf{Q}$ \\
\hline $2017 / 0023$ & Waddenzee kustzone oost & 0,7 & 0,6 & 2,1 & $<0,4$ & $<0,3$ & $<0,3$ & 18,7 \\
\hline $2017 / 0064$ & Waddenzee kustzone west & 0,5 & 0,3 & 3,0 & $<0,3$ & $<0,3$ & $<0,2$ & 17,3 \\
\hline $2017 / 0105$ & Hollandse kustzone noord & 0,6 & $<0,5$ & 2,8 & $<0,5$ & $<0,4$ & 0,6 & 29,1 \\
\hline $2017 / 0146$ & Hollandse kustzone midden & 0,5 & 0,4 & 1,9 & $<0,2$ & $<0,2$ & 0,2 & 23,9 \\
\hline $2017 / 0187$ & Hollandse kustzone zuid & 0,6 & 0,5 & 2,5 & $<0,4$ & $<0,3$ & 0,4 & 27,0 \\
\hline $2017 / 0228$ & Haringvliet kustzone & 0,6 & $<0,5$ & 1,5 & $<0,5$ & $<0,4$ & 0,6 & 26,9 \\
\hline $2017 / 0269$ & Grevelingen kustzone & 0,5 & $<0,3$ & 2,7 & $<0,3$ & $<0,3$ & 0,4 & 28,2 \\
\hline $2017 / 0310$ & Oosterschelde kustzone & 0,4 & 0,3 & 3,8 & $<0,3$ & $<0,2$ & 0,4 & 25,6 \\
\hline $2017 / 0351$ & Westerschelde kustzone & 0,6 & 1,0 & 6,5 & $<0,3$ & $<0,3$ & 0,4 & 22,9 \\
\hline
\end{tabular}

Tabel 10 Overzicht van de resultaten van de organotin gehalten uitgedrukt als kation in mariene slakken 2017.

\begin{tabular}{|l|l|c|c|c|c|c|c|}
\hline \multirow{2}{*}{ Monstercode } & Gebied & \multicolumn{6}{|c|}{ Resultaten Organotin ( $\mu$ kation/kg) } \\
\cline { 3 - 8 } & & MBT & DBT & TBT & MPhT & DPhT & TPhT \\
\hline & & & $\mathbf{Q}$ & $\mathbf{Q}$ & & & \\
\hline $2017 / 0023$ & Waddenzee kustzone oost & 1,1 & 1,1 & 5,1 & $<0,6$ & $<0,7$ & $<0,8$ \\
\hline $2017 / 0064$ & Waddenzee kustzone west & 0,7 & 0,7 & 7,3 & $<0,5$ & $<0,6$ & $<0,7$ \\
\hline $2017 / 0105$ & Hollandse kustzone noord & 0,8 & $<0,9$ & 6,9 & $<0,8$ & $<1,0$ & 2,0 \\
\hline $2017 / 0146$ & Hollandse kustzone midden & 0,8 & 0,7 & 4,7 & $<0,4$ & $<0,5$ & 0,8 \\
\hline $2017 / 0187$ & Hollandse kustzone zuid & 0,9 & 1,0 & 6,2 & $<0,6$ & $<0,7$ & 1,3 \\
\hline $2017 / 0228$ & Haringvliet kustzone & 0,9 & $<1,0$ & 3,8 & $<0,8$ & $<1,0$ & 1,7 \\
\hline $2017 / 0269$ & Grevelingen kustzone & 0,7 & $<0,6$ & 6,6 & $<0,5$ & $<0,6$ & 1,3 \\
\hline $2017 / 0310$ & Oosterschelde kustzone & 0,6 & 0,6 & 9,4 & $<0,5$ & $<0,6$ & 1,3 \\
\hline $2017 / 0351$ & Westerschelde kustzone & 0,9 & 1,9 & 16 & $<0,5$ & $<0,7$ & 1,3 \\
\hline
\end{tabular}


Voor de bepalingen van de organotinverbindingen en droge stof voldoen de metingen aan de kwaliteitscriteria, zoals gesteld in de geaccrediteerde werkvoorschriften. Aangezien de metingen van de organotinverbindingen en droge stof voldoen aan alle kwaliteitscriteria, zoals genoemd in betreffend ISW, zijn de gerapporteerde gehalten als normale waarden (met kwaliteitswaardecode 0) gerapporteerd. Voor de organotinverbindingen vallen alleen de metingen van TBT en DBT onder accreditatie, en daarom worden alleen deze resultaten met het kwaliteitskenmerk Q gerapporteerd. De droge stof bepaling valt onder de accreditatie en resultaten worden met het kwaliteitskenmerk $\mathrm{Q}$ gerapporteerd.

In Bijlage 3.1 zijn de gemeten gehalten in een mee-geanalyseerd referentiemateriaal weergegeven. Het betreft het gecertificeerde referentiemateriaal mossel (CRM CE-477). De door WMR gemeten gehalten in dit monster worden voor de componenten TBT, DBT en MBT binnen de 2 s-grenzen van de gecertificeerde waarden teruggevonden en kunnen dus als goed gekwalificeerd worden. Voor de overige organotin componenten zijn geen gecertificeerde waarden vastgesteld voor dit CRM.

In Bijlage 3.2 zijn de resultaten van deelname aan Quasimeme ringonderzoeken weergegeven. De zscores voldeden alle aan het door Quasimeme gestelde criterium.

In Bijlage 3.3 zijn de rapportagegrenzen en meetonzekerheden weergegeven. Hierover kan het volgende worden vermeld:

De rapportagegrenzen voor de anorganische componenten en voor de metalen zijn vaste grenzen die zijn vastgesteld uit de historie van de blanco bepalingen. De rapportagegrenzen voor de organische componenten worden vastgesteld aan de hand van de laagst gemeten standaard. De rapportagegrens is afhankelijk van de hoeveelheid ingewogen monster en is dus eigenlijk voor ieder monster verschillend, de compromis rapportagegrenzen zijn in Bijlage 3.3 weergegeven. De OSPAR-richtlijn voor de rapportagegrens voor TBT is $1 \mu \mathrm{g} / \mathrm{kg}$ nat gewicht uitgedrukt als kation en $0.4 \mu \mathrm{g} / \mathrm{kg}$ nat gewicht uitgedrukt als Sn (OSPAR Agreement, 2008-09). De gerapporteerde rapportagegrenzen (0,5$0,8 \mu \mathrm{g} / \mathrm{kg}$ nat gewicht uitgedrukt als kation en $0,2-0,3 \mu \mathrm{g} / \mathrm{kg}$ nat gewicht uitgedrukt als $\mathrm{Sn}$ ) voldoen ruimschoots aan boven gestelde richtlijn voor de rapportagegrenzen voor TBT.

De meetonzekerheid wordt door WMR volgens NEN7779 bepaald, met RMS (root mean square) als uitgangspunt. Hierbij wordt uit de standaardonzekerheid de uitgebreide (meet)onzekerheid berekend. Dit is het $95 \%$ betrouwbaarheidsinterval dat in de meetwaarden gebruikt wordt.

Als basis voor de bepaling van de meetonzekerheid als relatieve waarde met interne laboratoriumgegevens en met de berekening RMS als uitgangspunt zijn er drie mogelijkheden:

1. Ringonderzoek (afgedekt zijn: reproduceerbaarheid, juistheid en tussenmonsterspreiding)

2. CRM (afgedekt zijn reproduceerbaarheid en juistheid)

3. Terugvinding (afgedekt zijn reproduceerbaarheid en juistheid)

Door de selectie van de gegevensbronnen zijn de vereiste parameters reproduceerbaarheid, gemiddelde methode-juistheid, tussen-monsterspreiding en monsterinhomogeniteit zo goed mogelijk afgedekt.

De volgende formule uit NEN7779 wordt hiervoor gebruikt:

$$
U_{r e l}=2 u_{r e l}=2 R M S_{r e l}=2 \sqrt{\frac{1}{n} \sum_{i=1}^{n}\left(\frac{y_{i}-\mu_{i}}{\mu_{i}}\right)^{2}}
$$

Waarin:

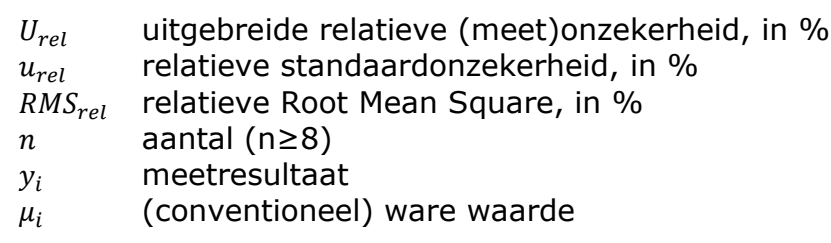


Voor de rapportage aan OSPAR door RWS wordt het 95\% betrouwbaarheidsinterval van de meetwaarde aangeleverd. Dit is de $U_{\text {rel }}$ uit bovenstaande formule. OSPAR gebruikt hiervoor echter een $U_{\mathrm{c}}$ (de absolute uitgebreide meetonzekerheid, in eenheid van concentratie component), berekend op basis van de volgende twee formules uit de OSPAR guideline:

$$
s_{\mathrm{c}}=\sqrt{d_{\mathrm{c}}^{2}+\left(\frac{v c}{100}\right)^{2}} C^{2}
$$

waarin:

$s_{\mathrm{c}} \quad$ standaarddeviatie, in eenheid van concentratie component

$d_{c} \quad$ gecombineerde constante fout, in eenheid van concentratie component

$v c \quad$ variatiecoëfficiënt, in \%

C concentratie van de component in het monster (meetwaarde)

$$
U_{\mathrm{c}}=2 s_{\mathrm{c}}
$$

waarin:

$U_{\mathrm{c}} \quad$ absolute uitgebreide (meet)onzekerheid, in eenheid van concentratie component $s_{\mathrm{c}} \quad$ standaarddeviatie, in eenheid van concentratie component

In Bijlage 3.3 worden de vereiste parameters voor deze OSPAR-berekening getoond. 


\section{$5 \quad$ Kwaliteitsborging}

Wageningen Marine Research beschikt over een ISO 9001:2008 gecertificeerd kwaliteitsmanagementsysteem (certificaatnummer: 187378-2015-AQ-NLD-RvA). Dit certificaat is geldig tot 15 december 2018. De organisatie is gecertificeerd sinds 27 februari 2001. De certificering is uitgevoerd door DNV Certification B.V.

Het chemisch laboratorium te IJmuiden beschikt over een NEN-EN-ISO/IEC 17025:2005 accreditatie voor testlaboratoria met nummer L097. Deze accreditatie is geldig tot 1 april 2021 en is voor het eerst verleend op 27 maart 1997; deze accreditatie is verleend door de Raad voor Accreditatie. Het chemisch laboratorium heeft hierdoor aangetoond in staat te zijn op technisch bekwame wijze valide resultaten te leveren en te werken volgens de ISO17025 norm. De scope (L097) met de geaccrediteerde analysemethoden is te vinden op de website van de Raad voor Accreditatie (www.rva.nl).

Op grond van deze accreditatie is het kwaliteitskenmerk $Q$ toegekend aan de resultaten van die componenten die op de scope staan vermeld, mits aan alle kwaliteitseisen is voldaan. Het kwaliteitskenmerk Q staat vermeld in de tabellen met de onderzoeksresultaten. Indien het kwaliteitskenmerk $Q$ niet staat vermeld is de reden hiervan vermeld.

De kwaliteit van de analysemethoden wordt op verschillende manieren gewaarborgd. De juistheid van de analysemethoden wordt regelmatig getoetst door deelname aan ringonderzoeken waaronder die georganiseerd door QUASIMEME. Indien geen ringonderzoek voorhanden is, wordt een tweede lijnscontrole uitgevoerd. Tevens wordt bij iedere meetserie een eerstelijnscontrole uitgevoerd. Naast de lijnscontroles wordende volgende algemene kwaliteitscontroles uitgevoerd:

- Blanco onderzoek.

- Terugvinding (recovery).

- $\quad$ Interne standaard voor borging opwerkmethode.

- Injectie standaard.

- Gevoeligheid.

Bovenstaande controles staan beschreven in Wageningen Marine Research werkvoorschrift ISW 2.10.2.105. Indien sprake is van onbeheerste kwaliteit worden passende maatregelen genomen.

Indien gewenst kunnen gegevens met betrekking tot de prestatiekenmerken van de analysemethoden bij het chemisch laboratorium worden opgevraagd. 


\section{Literatuur}

Bauer B., P. Fioroni, I. Ide, S. Liebe, J. Oehlmann, E. Stroben \& B. Watermann (1995) TBT effects on the female genital system of Littorina littorea: A possible indicator of tributyltin pollution. Hydrobiologia 309:15-27.

Bryan G.W., G.R. Burt, P.E. Gibbs \& P.L. Pascoe (1993) Nassarius reticulatus (Nassariidae: Gastropoda) as an indicator of tributyltin pollution before and after TBT restrictions. J. Mar. Biol. Ass. U.K. 73(4):913-929.

Hoek-van Nieuwenhuizen, M. \& J. Jol en N.H.B.M. Kaag (2013) TBT-gehalten en effecten bij de Gewone Alikruik, de Gevlochten Fuikhoorn en de Purperslak langs de Nederlandse kust in 2013. IMARES rapport C176/13.

Hoek-van Nieuwenhuizen, M. \& J. Jol en N.H.B.M. Kaag (2014) TBT-gehalten en effecten bij de Gewone Alikruik, de Gevlochten Fuikhoorn en de Purperslak langs de Nederlandse kust in 2014. IMARES rapport C148/14.

Hoek-van Nieuwenhuizen M., J. Jol en N.H.B.M. Kaag (2015) TBT-gehalten en effecten bij de Gewone Alikruik, de Gevlochten Fuikhoorn en de Purperslak langs de Nederlandse kust in 2015. IMARES rapport C147/15.

Jol J. (2004) Vaststellen van intersex bij de Gewone Alikruik (Littorina littorea L.). RIKZ standaardvoorschrift SPECIE-11.

Jol J. (2007) Vaststellen van imposex bij de Purperslak (Nucella lapillus L.). RIKZ standaardvoorschrift SPECIE-12.

Kaag N.H.B.M. \& J. Jol (2007) Monitoring imposex bij de purperslak, Nucella lapillus, in de Zeeuwse wateren. IMARES rapport C112/07.

Kaag N.H.B.M., J. Jol \& M. Hoek-van Nieuwenhuizen (2009) TBT-gehalten en effecten bij de Gewone Alikruik (Littorina littorea) en de Gevlochten Fuikhoorn (Nassarius reticulatus) langs de Nederlandse kust in 2009. IMARES rapport C113/09.

Kotterman, M. J. Jol en E van Barneveld (2016) TBT-gehalten en effecten bij de Gewone Alikruik, de Gevlochten Fuikhoorn en de Purperslak langs de Nederlandse kust in 2016. IMARES rapport C110/16.

Oehlmann J., E. Stroben, U. Schulte-Oehlmann, B. Bauer, P. Fioroni \& B. Markert (1996) Tributyltin biomonitoring using prosobranchs as sentinel organisms. Fresenius J. Anal. Chem. 354(5-6):540545.

OSPAR (2008) JAMP Guidelines for Contamination Specific Biological Effects. OSPAR Agreement 200809.

Stroben E., J. Oehlmann \& P. Fioroni (1992a) Hinia reticulata and Nucella lapillus. Comparison of two gastropod tributyltin bioindicators. Mar. Biol. 114:289-296.

Weijden, M.H. van der (2015). Projectplan chemisch meetnet MWTL 2014. Monitoring van organotinverbindingen en biologische effecten in mariene slak, 27 oktober 2014 (concept). 


\section{Verantwoording}

Rapport C058.18

Projectnummer: 43.161 .000 .91

Dit rapport is met grote zorgvuldigheid tot stand gekomen. De wetenschappelijke kwaliteit is intern getoetst door een collega-onderzoeker en het verantwoordelijk lid van het managementteam van Wageningen Marine Research

Akkoord:

Handtekening:

Datum:

23 november 2018

Akkoord:

Handtekening:

Datum:

Drs. J. Asjes

MT lid Integratie

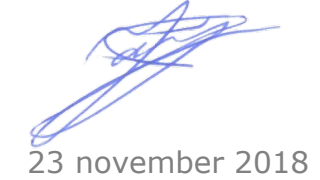


Wageningen Marine Research

T: $+31(0) 317480900$

E: marine-research@wur.nl

www.wur.nl/marine-research

Visitors address

- Ankerpark 271781 AG Den Helder

- Korringaweg 7, 4401 NT Yerseke

- Haringkade 1, 1976 CP IJmuiden
Wageningen Marine Research is the Netherlands research institute established to provide the scientific support that is essential for developing policies and innovation in respect of the marine environment, fishery activities, aquaculture and the maritime sector.

Wageningen University \& Research is specialised in the domain of healthy food and living environment.

\section{The Wageningen Marine Research vision:}

'To explore the potential of marine nature to improve the quality of life.'

\section{The Wageningen Marine Research mission}

- To conduct research with the aim of acquiring knowledge and offering advice on the sustainable management and use of marine and coastal areas.

- Wageningen Marine Research is an independent, leading scientific research institute.

Wageningen Marine Research is part of the international knowledge organisation Wageningen UR (University \& Research centre). Within Wageningen UR, nine specialised research institutes of Stichting Wageningen Research (a Foundation) have joined forces with Wageningen University to help answer the most important questions in the domain of healthy food and living environment. 


\section{Bijlagen rapport C058.18 Mariene slakken: $1.1 \mathrm{t} / \mathrm{m} 3.3$}


Bijlage 1.1: Resultaten intersex analyse Alikruiken

\begin{tabular}{|c|c|c|c|c|c|c|c|c|c|c|c|c|c|c|c|}
\hline \multirow[t]{2}{*}{ Requestnummer } & \multirow{2}{*}{$\begin{array}{l}\text { Monster } \\
\text { soort }\end{array}$} & \multirow[t]{2}{*}{ Gebied } & \multirow[t]{2}{*}{ DONAR locatie } & \multirow{2}{*}{$\begin{array}{l}\text { Bemonster } \\
\text { datum }\end{array}$} & \multirow{2}{*}{$\begin{array}{c}\text { Aantal } \\
\text { onderzocht }\end{array}$} & \multirow{2}{*}{$\begin{array}{c}\text { Aantal } \\
\text { vrouwtjes }\end{array}$} & \multirow{2}{*}{$\begin{array}{c}\text { Gemiddelde } \\
\text { penislengte } \\
\text { vrouwtjes }\end{array}$} & \multirow{2}{*}{$\begin{array}{l}\text { Gemiddelde } \\
\text { penislengte } \\
\text { mannetjes }\end{array}$} & \multirow{2}{*}{$\begin{array}{c}\text { Aantal vrouwtjes } \\
\text { met intersex }\end{array}$} & \multicolumn{5}{|c|}{ Stadium } & \multirow[t]{2}{*}{ ISI } \\
\hline & & & & & & & & & & 0 & 1 & 2 & 3 & 4 & \\
\hline RQ20170209/004 & Alikruik & $\begin{array}{l}\text { Waddenzee } \\
\text { kustzone oost }\end{array}$ & WADDZKZNOT & $16 / \mathrm{mrt} / 17$ & 40 & 20 & 0.000 & 4.765 & 0 & 20 & 0 & 0 & 0 & 0 & $\mathrm{nb}$ \\
\hline RQ20170209/005 & Alikruik & $\begin{array}{l}\text { Waddenzee } \\
\text { kustzone west }\end{array}$ & WADDZKZNWT & $16 / \mathrm{mrt} / 17$ & 40 & 18 & 0.000 & 4.391 & 0 & 18 & 0 & 0 & 0 & 0 & $\mathrm{nb}$ \\
\hline
\end{tabular}




\begin{tabular}{|c|c|c|c|c|c|c|c|c|c|c|c|c|}
\hline Requestnummer & $\begin{array}{l}\text { Monster } \\
\text { nummer }\end{array}$ & Nr. & Locatie & $\begin{array}{l}\text { DONAR } \\
\text { locatie }\end{array}$ & $\begin{array}{l}\text { Bemonster } \\
\text { datum }\end{array}$ & \begin{tabular}{|c|} 
Geslacht \\
$M=1, V=2$, \\
$p=3$
\end{tabular} & \begin{tabular}{|c|} 
Totale \\
gewicht \\
$(\mathrm{g}-1$ \\
$\mathrm{dec})$
\end{tabular} & $\begin{array}{l}\begin{array}{l}\text { Lengte } \\
\text { schelp } \\
(\mathrm{mm}- \\
1 \mathrm{dec})\end{array} \\
\end{array}$ & $\begin{array}{c}\text { Gewicht } \\
\text { vlees } \\
(\mathrm{g}- \\
1 \mathrm{dec})\end{array}$ & $\begin{array}{c}\text { Penislengte } \\
\text { vrouw } \\
(\mathrm{mm}-1 \mathrm{dec})\end{array}$ & $\begin{array}{c}\text { Penislengte } \\
\text { man } \\
(\mathrm{mm}-1 \mathrm{dec})\end{array}$ & $\begin{array}{c}\text { Stadium } \\
0,1,2,3 \\
\text { etc } a, b, c \\
\text { etc }\end{array}$ \\
\hline RQ20170209/004 & $2017 / 0024$ & 1 & Waddenzee kustzone oost & WADDZKZNOT & 16 / mrt / 2017 & 2 & 2.5 & 19.7 & 0.8 & 0 & & 0 \\
\hline RQ20170209/004 & $2017 / 0025$ & 2 & Waddenzee kustzone oost & WADDZKZNOT & 16 / mrt / 2017 & 1 & 2.8 & 20.3 & 0.6 & & 3.5 & \\
\hline RQ20170209/004 & $2017 / 0026$ & 3 & Waddenzee kustzone oost & WADDZKZNOT & $16 / \mathrm{mrt} / 2017$ & 2 & 4.0 & 22.2 & 0.8 & 0 & & 0 \\
\hline RQ20170209/004 & $2017 / 0027$ & 4 & Waddenzee kustzone oost & WADDZKZNOT & $16 / \mathrm{mrt} / 2017$ & 2 & 3.4 & 20.4 & 0.7 & 0 & & 0 \\
\hline RQ20170209/004 & $2017 / 0028$ & 5 & Waddenzee kustzone oost & WADDZKZNOT & 16 / mrt / 2017 & 1 & 3.0 & 19.5 & 0.8 & & 5.0 & \\
\hline RQ20170209/004 & $2017 / 0029$ & 6 & Waddenzee kustzone oost & WADDZKZNOT & 16 / mrt / 2017 & 2 & 3.4 & 20.4 & 0.8 & 0 & & 0 \\
\hline RQ20170209/004 & $2017 / 0030$ & 7 & Waddenzee kustzone oost & WADDZKZNOT & $16 / \mathrm{mrt} / 2017$ & 1 & 3.1 & 19.6 & 0.7 & & 4.5 & \\
\hline RQ20170209/004 & $2017 / 0031$ & 8 & Waddenzee kustzone oost & WADDZKZNOT & 16 / mrt / 2017 & 1 & 3.5 & 20.4 & 0.8 & & 5.2 & \\
\hline RQ20170209/004 & $2017 / 0032$ & 9 & Waddenzee kustzone oost & WADDZKZNOT & $16 / \mathrm{mrt} / 2017$ & 1 & 4.1 & 22.7 & 1 & & 4.0 & \\
\hline RQ20170209/004 & $2017 / 0033$ & 10 & Waddenzee kustzone oost & WADDZKZNOT & 16 / mrt / 2017 & 2 & 2.5 & 17.4 & 0.5 & 0 & & 0 \\
\hline RQ20170209/004 & $2017 / 0034$ & 11 & Waddenzee kustzone oost & WADDZKZNOT & 16 / mrt / 2017 & 1 & 3.9 & 22.8 & 0.6 & & 4.8 & \\
\hline RQ20170209/004 & $2017 / 0035$ & 12 & Waddenzee kustzone oost & WADDZKZNOT & 16 / mrt / 2017 & 1 & 4.1 & 22.1 & 0.9 & & 4.4 & \\
\hline RQ20170209/004 & $2017 / 0036$ & 13 & Waddenzee kustzone oost & WADDZKZNOT & 16 / mrt / 2017 & 1 & 3.5 & 20.7 & 0.9 & & 4.2 & \\
\hline RQ20170209/004 & $2017 / 0037$ & 14 & Waddenzee kustzone oost & WADDZKZNOT & $16 / \mathrm{mrt} / 2017$ & 1 & 3.1 & 20.1 & 0.8 & & 5.2 & \\
\hline RQ20170209/004 & $2017 / 0038$ & 15 & Waddenzee kustzone oost & WADDZKZNOT & $16 / \mathrm{mrt} / 2017$ & 1 & 4.1 & 23.8 & 1 & & 6.0 & \\
\hline RQ20170209/004 & $2017 / 0039$ & 16 & Waddenzee kustzone oost & WADDZKZNOT & $16 / \mathrm{mrt} / 2017$ & 1 & 3.6 & 20.2 & 0.8 & & 4.5 & \\
\hline RQ20170209/004 & $2017 / 0040$ & 17 & Waddenzee kustzone oost & WADDZKZNOT & $16 / \mathrm{mrt} / 2017$ & 1 & 4.6 & 23.1 & 0.7 & & 4.0 & \\
\hline RQ20170209/004 & $2017 / 0041$ & 18 & Waddenzee kustzone oost & WADDZKZNOT & $16 / \mathrm{mrt} / 2017$ & 1 & 2.9 & 19.5 & 0.7 & & 5.0 & \\
\hline RQ20170209/004 & $2017 / 0042$ & 19 & Waddenzee kustzone oost & WADDZKZNOT & $16 / \mathrm{mrt} / 2017$ & 2 & 4.0 & 22.5 & 1 & 0 & & 0 \\
\hline RQ20170209/004 & $2017 / 0043$ & 20 & Waddenzee kustzone oost & WADDZKZNOT & $16 / \mathrm{mrt} / 2017$ & 2 & 3.3 & 20.8 & 0.8 & 0 & & 0 \\
\hline RQ20170209/004 & $2017 / 0044$ & 21 & Waddenzee kustzone oost & WADDZKZNOT & $16 / \mathrm{mrt} / 2017$ & 2 & 4.6 & 24.6 & 1.1 & 0 & & 0 \\
\hline RQ20170209/004 & $2017 / 0045$ & 22 & Waddenzee kustzone oost & WADDZKZNOT & $16 / \mathrm{mrt} / 2017$ & 1 & 3.6 & 21.5 & 1 & & 6.8 & \\
\hline RQ20170209/004 & $2017 / 0046$ & 23 & Waddenzee kustzone oost & WADDZKZNOT & $16 / \mathrm{mrt} / 2017$ & 1 & 3.3 & 20.1 & 0.8 & & 4.7 & \\
\hline RQ20170209/004 & $2017 / 0047$ & 24 & Waddenzee kustzone oost & WADDZKZNOT & $16 / \mathrm{mrt} / 2017$ & 1 & 3.8 & 21.4 & 0.9 & & 5.5 & \\
\hline RQ20170209/004 & $2017 / 0048$ & 25 & Waddenzee kustzone oost & WADDZKZNOT & 16 / mrt / 2017 & 2 & 3.4 & 21.0 & 1 & 0 & & 0 \\
\hline RQ20170209/004 & $2017 / 0049$ & 26 & Waddenzee kustzone oost & WADDZKZNOT & $16 / \mathrm{mrt} / 2017$ & 2 & 2.7 & 19.2 & 0.6 & 0 & & 0 \\
\hline RQ20170209/004 & $2017 / 0050$ & 27 & Waddenzee kustzone oost & WADDZKZNOT & $16 / \mathrm{mrt} / 2017$ & 1 & 3.1 & 20.0 & 0.6 & & 3.9 & \\
\hline RQ20170209/004 & $2017 / 0051$ & 28 & Waddenzee kustzone oost & WADDZKZNOT & 16 / mrt / 2017 & 1 & 2.8 & 19.9 & 0.6 & & 3.5 & \\
\hline RQ20170209/004 & $2017 / 0052$ & 29 & Waddenzee kustzone oost & WADDZKZNOT & 16 / mrt / 2017 & 2 & 2.8 & 19.2 & 0.7 & 0 & & 0 \\
\hline RQ20170209/004 & $2017 / 0053$ & 30 & Waddenzee kustzone oost & WADDZKZNOT & $16 / \mathrm{mrt} / 2017$ & 2 & 2.8 & 19.6 & 0.6 & 0 & & 0 \\
\hline RQ20170209/004 & $2017 / 0054$ & 31 & Waddenzee kustzone oost & WADDZKZNOT & $16 / \mathrm{mrt} / 2017$ & 2 & 3.8 & 21.8 & 0.9 & 0 & & 0 \\
\hline RQ20170209/004 & $2017 / 0055$ & 32 & Waddenzee kustzone oost & WADDZKZNOT & $16 / \mathrm{mrt} / 2017$ & 1 & 4.0 & 22.1 & 0.9 & & 5.2 & \\
\hline RQ20170209/004 & $2017 / 0056$ & 33 & Waddenzee kustzone oost & WADDZKZNOT & $16 / \mathrm{mrt} / 2017$ & 2 & 3.3 & 20.1 & 0.8 & 0 & & 0 \\
\hline RQ20170209/004 & $2017 / 0057$ & 34 & Waddenzee kustzone oost & WADDZKZNOT & 16 / mrt / 2017 & 2 & 2.1 & 20.2 & 0.8 & 0 & & 0 \\
\hline RQ20170209/004 & $2017 / 0058$ & 35 & Waddenzee kustzone oost & WADDZKZNOT & 16 / mrt / 2017 & 2 & 2.9 & 19.0 & 0.6 & 0 & & 0 \\
\hline RQ20170209/004 & $2017 / 0059$ & 36 & Waddenzee kustzone oost & WADDZKZNOT & $16 / \mathrm{mrt} / 2017$ & 2 & 3.4 & 20.8 & 0.8 & 0 & & 0 \\
\hline RQ20170209/004 & $2017 / 0060$ & 37 & Waddenzee kustzone oost & WADDZKZNOT & $16 / \mathrm{mrt} / 2017$ & 2 & 3.5 & 20.2 & 0.8 & 0 & & 0 \\
\hline RQ20170209/004 & $2017 / 0061$ & 38 & Waddenzee kustzone oost & WADDZKZNOT & $16 / \mathrm{mrt} / 2017$ & 1 & 3.0 & 19.5 & 0.7 & & 5.4 & \\
\hline RQ20170209/004 & $2017 / 0062$ & 39 & Waddenzee kustzone oost & WADDZKZNOT & $16 / \mathrm{mrt} / 2017$ & 2 & 3.2 & 19.9 & 0.9 & 0 & & 0 \\
\hline RQ20170209/004 & $2017 / 0063$ & 40 & Waddenzee kustzone oost & WADDZKZNOT & $16 / \mathrm{mrt} / 2017$ & 2 & 3.2 & 20.3 & 0.8 & 0 & & 0 \\
\hline
\end{tabular}




\begin{tabular}{|c|c|c|c|c|c|c|c|c|c|c|c|c|}
\hline Requestnummer & $\begin{array}{l}\text { Monster } \\
\text { nummer }\end{array}$ & $\mathrm{Nr}$. & Locatie & $\begin{array}{l}\text { DONAR } \\
\text { locatie }\end{array}$ & $\begin{array}{c}\text { Bemonster } \\
\text { datum }\end{array}$ & $\begin{array}{c}\text { Geslacht } \\
M=1, V=2, \\
p=3\end{array}$ & \begin{tabular}{|c|} 
Totale \\
gewicht \\
$(\mathrm{g}-1$ \\
$\mathrm{dec})$
\end{tabular} & $\begin{array}{l}\begin{array}{l}\text { Lengte } \\
\text { schelp } \\
(\mathrm{mm}- \\
1 \mathrm{dec})\end{array} \\
\end{array}$ & $\begin{array}{c}\text { Gewicht } \\
\text { vlees } \\
(\mathrm{g}- \\
1 \mathrm{dec})\end{array}$ & $\begin{array}{c}\text { Penislengte } \\
\text { vrouw } \\
(\mathrm{mm}-1 \mathrm{dec})\end{array}$ & $\begin{array}{c}\text { Penislengte } \\
\text { man } \\
(\mathrm{mm}-1 \mathrm{dec})\end{array}$ & $\begin{array}{c}\text { Stadium } \\
0,1,2,3 \\
\text { etc a,b,c } \\
\text { etc }\end{array}$ \\
\hline RQ20170209/005 & $2017 / 0065$ & 1 & Waddenzee kustzone west & WADDZKZNWT & $16 / \mathrm{mrt} / 2017$ & 2 & 5.6 & 21.5 & 0.8 & 0 & & 0 \\
\hline RQ20170209/005 & $2017 / 0066$ & 2 & Waddenzee kustzone west & WADDZKZNWT & $16 / \mathrm{mrt} / 2017$ & 1 & 2.4 & 18.9 & 0.6 & & 3.4 & \\
\hline RQ20170209/005 & $2017 / 0067$ & 3 & Waddenzee kustzone west & WADDZKZNWT & $16 / \mathrm{mrt} / 2017$ & 1 & 3.6 & 21.1 & 0.8 & & 4.6 & \\
\hline RQ20170209/005 & $2017 / 0068$ & 4 & Waddenzee kustzone west & WADDZKZNWT & $16 / \mathrm{mrt} / 2017$ & 2 & 3.7 & 21.0 & 0.8 & 0 & & 0 \\
\hline RQ20170209/005 & $2017 / 0069$ & 5 & Waddenzee kustzone west & WADDZKZNWT & 16 / mrt / 2017 & 1 & 2.6 & 17.8 & 0.5 & & 4.0 & \\
\hline RQ20170209/005 & $2017 / 0070$ & 6 & Waddenzee kustzone west & WADDZKZNWT & $16 / \mathrm{mrt} / 2017$ & 1 & 3.2 & 20.6 & 0.7 & & 4.7 & \\
\hline RQ20170209/005 & $2017 / 0071$ & 7 & Waddenzee kustzone west & WADDZKZNWT & $16 / \mathrm{mrt} / 2017$ & 1 & 2.0 & 17.5 & 0.6 & & 5.5 & \\
\hline RQ20170209/005 & $2017 / 0072$ & 8 & Waddenzee kustzone west & WADDZKZNWT & $16 / \mathrm{mrt} / 2017$ & 2 & 2.8 & 19.0 & 0.5 & 0 & & 0 \\
\hline RQ20170209/005 & $2017 / 0073$ & 9 & Waddenzee kustzone west & WADDZKZNWT & $16 / \mathrm{mrt} / 2017$ & 2 & 2.9 & 19.3 & 0.5 & 0 & & 0 \\
\hline RQ20170209/005 & $2017 / 0074$ & 10 & Waddenzee kustzone west & WADDZKZNWT & 16 / mrt / 2017 & 1 & 2.3 & 18.4 & 0.6 & & 5.4 & \\
\hline RQ20170209/005 & $2017 / 0075$ & 11 & Waddenzee kustzone west & WADDZKZNWT & $16 / \mathrm{mrt} / 2017$ & 1 & 4.9 & 24.0 & 1.1 & & 1.5 & \\
\hline RQ20170209/005 & $2017 / 0076$ & 12 & Waddenzee kustzone west & WADDZKZNWT & $16 / \mathrm{mrt} / 2017$ & 2 & 4.9 & 21.9 & 0.8 & 0 & & 0 \\
\hline RQ20170209/005 & $2017 / 0077$ & 13 & Waddenzee kustzone west & WADDZKZNWT & 16 / mrt / 2017 & 2 & 2.9 & 19.7 & 0.6 & 0 & & 0 \\
\hline RQ20170209/005 & $2017 / 0078$ & 14 & Waddenzee kustzone west & WADDZKZNWT & $16 / \mathrm{mrt} / 2017$ & 2 & 3.0 & 20.5 & 0.6 & 0 & & 0 \\
\hline RQ20170209/005 & $2017 / 0079$ & 15 & Waddenzee kustzone west & WADDZKZNWT & $16 / \mathrm{mrt} / 2017$ & 2 & 3.2 & 20.2 & 0.7 & 0 & & 0 \\
\hline RQ20170209/005 & $2017 / 0080$ & 16 & Waddenzee kustzone west & WADDZKZNWT & 16 / mrt / 2017 & 1 & 3.7 & 20.8 & 0.6 & & 6.3 & \\
\hline RQ20170209/005 & $2017 / 0081$ & 17 & Waddenzee kustzone west & WADDZKZNWT & $16 / \mathrm{mrt} / 2017$ & 1 & 2.6 & 20.3 & 0.5 & & 4.5 & \\
\hline RQ20170209/005 & $2017 / 0082$ & 18 & Waddenzee kustzone west & WADDZKZNWT & $16 / \mathrm{mrt} / 2017$ & 2 & 2.7 & 20.5 & 0.6 & 0 & & 0 \\
\hline RQ20170209/005 & $2017 / 0083$ & 19 & Waddenzee kustzone west & WADDZKZNWT & $16 / \mathrm{mrt} / 2017$ & 2 & 2.5 & 20.0 & 0.6 & 0 & & 0 \\
\hline RQ20170209/005 & $2017 / 0084$ & 20 & Waddenzee kustzone west & WADDZKZNWT & $16 / \mathrm{mrt} / 2017$ & 1 & 2.3 & 18.5 & 0.6 & & 5.8 & \\
\hline RQ20170209/005 & $2017 / 0085$ & 21 & Waddenzee kustzone west & WADDZKZNWT & $16 / \mathrm{mrt} / 2017$ & 1 & 2.8 & 20.6 & 0.6 & & 4.8 & \\
\hline RQ20170209/005 & $2017 / 0086$ & 22 & Waddenzee kustzone west & WADDZKZNWT & $16 / \mathrm{mrt} / 2017$ & 2 & 4.0 & 22.3 & 0.9 & 0 & & 0 \\
\hline RQ20170209/005 & $2017 / 0087$ & 23 & Waddenzee kustzone west & WADDZKZNWT & 16 / mrt / 2017 & 1 & 3.7 & 21.6 & 0.7 & & 5.3 & \\
\hline RQ20170209/005 & $2017 / 0088$ & 24 & Waddenzee kustzone west & WADDZKZNWT & $16 / \mathrm{mrt} / 2017$ & 1 & 3.7 & 22.4 & 0.9 & & 4.8 & \\
\hline RQ20170209/005 & $2017 / 0089$ & 25 & Waddenzee kustzone west & WADDZKZNWT & $16 / \mathrm{mrt} / 2017$ & 1 & 3.1 & 21.1 & 0.9 & & 6.1 & \\
\hline RQ20170209/005 & $2017 / 0090$ & 26 & Waddenzee kustzone west & WADDZKZNWT & $16 / \mathrm{mrt} / 2017$ & 2 & 2.6 & 19.5 & 0.5 & 0 & & 0 \\
\hline RQ20170209/005 & $2017 / 0091$ & 27 & Waddenzee kustzone west & WADDZKZNWT & 16 / mrt / 2017 & 1 & 2.9 & 19.5 & 0.7 & & 5.2 & \\
\hline RQ20170209/005 & $2017 / 0092$ & 28 & Waddenzee kustzone west & WADDZKZNWT & $16 / \mathrm{mrt} / 2017$ & 2 & 2.1 & 18.2 & 0.4 & 0 & & 0 \\
\hline RQ20170209/005 & $2017 / 0093$ & 29 & Waddenzee kustzone west & WADDZKZNWT & 16 / mrt / 2017 & 1 & 2.6 & 18.5 & 0.5 & & 5.2 & \\
\hline RQ20170209/005 & $2017 / 0094$ & 30 & Waddenzee kustzone west & WADDZKZNWT & $16 / \mathrm{mrt} / 2017$ & 2 & 2.0 & 17.8 & 0.5 & 0 & & 0 \\
\hline RQ20170209/005 & $2017 / 0095$ & 31 & Waddenzee kustzone west & WADDZKZNWT & $16 / \mathrm{mrt} / 2017$ & 1 & 2.2 & 17.8 & 0.5 & & 5.2 & \\
\hline RQ20170209/005 & $2017 / 0096$ & 32 & Waddenzee kustzone west & WADDZKZNWT & $16 / \mathrm{mrt} / 2017$ & 2 & 2.4 & 18.6 & 0.6 & 0 & & 0 \\
\hline RQ20170209/005 & 2017/0097 & 33 & Waddenzee kustzone west & WADDZKZNWT & $16 / \mathrm{mrt} / 2017$ & 1 & 1.7 & 16.6 & 0.4 & & 2.8 & \\
\hline RQ20170209/005 & $2017 / 0098$ & 34 & Waddenzee kustzone west & WADDZKZNWT & 16 / mrt / 2017 & 2 & 1.6 & 16.2 & 0.3 & 0 & & 0 \\
\hline RQ20170209/005 & 2017/0099 & 35 & Waddenzee kustzone west & WADDZKZNWT & $16 / \mathrm{mrt} / 2017$ & 2 & 1.9 & 16.8 & 0.3 & 0 & & 0 \\
\hline RQ20170209/005 & $2017 / 0100$ & 36 & Waddenzee kustzone west & WADDZKZNWT & $16 / \mathrm{mrt} / 2017$ & 2 & 3.6 & 20.4 & 0.8 & 0 & & 0 \\
\hline RQ20170209/005 & $2017 / 0101$ & 37 & Waddenzee kustzone west & WADDZKZNWT & $16 / \mathrm{mrt} / 2017$ & 1 & 1.7 & 16.8 & 0.5 & & 3.8 & \\
\hline RQ20170209/005 & $2017 / 0102$ & 38 & Waddenzee kustzone west & WADDZKZNWT & $16 / \mathrm{mrt} / 2017$ & 1 & 1.4 & 15.1 & 0.3 & & 3.2 & \\
\hline RQ20170209/005 & 2017/0103 & 39 & Waddenzee kustzone west & WADDZKZNWT & $16 / \mathrm{mrt} / 2017$ & 1 & 1.3 & 14.4 & 0.3 & & 2.3 & \\
\hline RQ20170209/005 & 2017/0104 & 40 & Waddenzee kustzone west & WADDZKZNWT & 16 / mrt / 2017 & 1 & 1.4 & 15.0 & 0.2 & & 2.2 & \\
\hline
\end{tabular}


Bijlage 2.1: Resultaten imposex analyse Gevlochten Fuikhoorns en Purperslakken

\begin{tabular}{|c|c|c|c|c|c|c|c|c|c|c|c|c|c|c|c|c|c|c|}
\hline Request- & Monster soort & Gebied & DONAR locatie & Bemonster & Aantal & Aantal & Gemiddelde & Gemiddelde & Aantal & & & & tadic & & & & VDSI & RPSI \\
\hline & & & & & & & viverviges & mán & 1 & 0 & $1 a$ & $1 b$ & $1 \mathrm{c}$ & 2 & 3 & 4 & & \\
\hline $\begin{array}{l}\text { RQ2017 } \\
\text { 0209/006 }\end{array}$ & $\begin{array}{l}\text { Gevlochten } \\
\text { Fuikhoorn }\end{array}$ & $\begin{array}{l}\text { Hollandse } \\
\text { kustzone } \\
\text { Noord }\end{array}$ & HOLLSKZNND & 18/apr/17 & 40 & 21 & 0.000 & 13.342 & 0 & 21 & 0 & 0 & 0 & 0 & 0 & 0 & $\mathrm{nb}$ & $\mathrm{nb}$ \\
\hline $\begin{array}{l}\text { RQ2017 } \\
\text { 0209/007 }\end{array}$ & $\begin{array}{l}\text { Gevlochten } \\
\text { Fuikhoorn }\end{array}$ & $\begin{array}{l}\text { Hollandse } \\
\text { kustzone } \\
\text { Midden }\end{array}$ & HOLLSKZNMDN & $29 / \mathrm{mrt} / 17$ & 40 & 26 & 0.000 & 10.986 & 0 & 26 & 0 & 0 & 0 & 0 & 0 & 0 & $\mathrm{nb}$ & $\mathrm{nb}$ \\
\hline $\begin{array}{l}\text { RQ2017 } \\
0209 / 008\end{array}$ & $\begin{array}{l}\text { Gevlochten } \\
\text { Fuikhoorn }\end{array}$ & $\begin{array}{l}\text { Hollandse } \\
\text { kustzone } \\
\text { Zuid }\end{array}$ & HOLLSKZNZD & 10/apr/17 & 40 & 21 & 0.000 & 14.789 & 0 & 21 & 0 & 0 & 0 & 0 & 0 & 0 & $\mathrm{nb}$ & $\mathrm{nb}$ \\
\hline $\begin{array}{l}\text { RQ2017 } \\
\text { 0209/009 }\end{array}$ & $\begin{array}{l}\text { Gevlochten } \\
\text { Fuikhoorn }\end{array}$ & $\begin{array}{l}\text { Haringvliet } \\
\text { kustzone }\end{array}$ & HARVKZNE & 12/apr/17 & 40 & 16 & 0.000 & 13.021 & 0 & 16 & 0 & 0 & 0 & 0 & 0 & 0 & $\mathrm{nb}$ & $\mathrm{nb}$ \\
\hline $\begin{array}{l}\text { RQ2017 } \\
0209 / 010\end{array}$ & Purperslak & $\begin{array}{l}\text { Grevelin- gen } \\
\text { kustzone }\end{array}$ & GREVLGKZNE & 13/mrt/17 & 40 & 15 & 0.000 & 5.064 & 2 & 13 & 0 & 0 & 2 & 0 & 0 & 0 & 0.13 & 0.000000 \\
\hline $\begin{array}{l}\text { RQ2017 } \\
\text { 0209/011 }\end{array}$ & Purperslak & $\begin{array}{l}\text { Ooster- } \\
\text { schelde } \\
\text { kustzone }\end{array}$ & OOSTSDKZNE & $13 / \mathrm{mrt} / 17$ & 40 & 23 & 0.000 & 3.953 & 0 & 23 & 0 & 0 & 0 & 0 & 0 & 0 & $\mathrm{nb}$ & $\mathrm{nb}$ \\
\hline $\begin{array}{l}\text { RQ2017 } \\
\text { 0209/012 }\end{array}$ & Purperslak & $\begin{array}{l}\text { Wester- } \\
\text { schelde } \\
\text { kustzone }\end{array}$ & WESTSDKZNE & $13 / \mathrm{mrt} / 17$ & 40 & 22 & 0.050 & 4.100 & 2 & 20 & 2 & 0 & 0 & 0 & 0 & 0 & 0.09 & 0.000181 \\
\hline
\end{tabular}




\begin{tabular}{|c|c|c|c|c|c|c|c|c|c|c|c|c|}
\hline Requestnummer & $\begin{array}{l}\text { Monster } \\
\text { nummer }\end{array}$ & $\mathrm{Nr}$. & Locatie & $\begin{array}{l}\text { DONAR } \\
\text { locatie }\end{array}$ & $\begin{array}{c}\text { Bemonster } \\
\text { datum }\end{array}$ & $\begin{array}{c}\text { Geslac } \\
\text { ht } \\
M=1 \\
V=2 \\
p=3\end{array}$ & $\begin{array}{c}\text { Totale } \\
\text { gewicht } \\
\text { (g-1 dec) }\end{array}$ & $\begin{array}{c}\text { Lengte } \\
\text { schelp } \\
\text { (mm-1dec) }\end{array}$ & $\begin{array}{l}\text { Gewicht } \\
\text { vlees } \\
\text { (g-1dec) }\end{array}$ & $\begin{array}{l}\text { Penis- } \\
\text { lengte } \\
\text { vrouw } \\
\text { (mm- } \\
1 \mathrm{dec})\end{array}$ & $\begin{array}{c}\text { Penis- } \\
\text { lengte } \\
\text { man } \\
(\mathrm{mm}- \\
1 \mathrm{dec})\end{array}$ & $\begin{array}{c}\text { Stadium } \\
0,1,2,3 \\
\text { a,b,c }\end{array}$ \\
\hline RQ20170209/006 & $2017 / 0106$ & 1 & Hollandse kustzone noord & HOLLSKZNND & 18 / apr / 2017 & 2 & 3.8 & 30.0 & 1.7 & 0 & & 0 \\
\hline RQ20170209/006 & $2017 / 0107$ & 2 & Hollandse kustzone noord & HOLLSKZNND & 18 / apr / 2017 & 2 & 3.9 & 29.3 & 1.8 & 0 & & 0 \\
\hline RQ20170209/006 & $2017 / 0108$ & 3 & Hollandse kustzone noord & HOLLSKZNND & 18 / apr / 2017 & 2 & 2.2 & 25.3 & 1.2 & 0 & & 0 \\
\hline RQ20170209/006 & $2017 / 0109$ & 4 & Hollandse kustzone noord & HOLLSKZNND & 18 / apr / 2017 & 1 & 2.7 & 26.1 & 1 & & 14 & \\
\hline RQ20170209/006 & $2017 / 0110$ & 5 & Hollandse kustzone noord & HOLLSKZNND & 18 / apr / 2017 & 1 & 2.4 & 24.8 & 1.1 & & 13.5 & \\
\hline RQ20170209/006 & $2017 / 0111$ & 6 & Hollandse kustzone noord & HOLLSKZNND & 18 / apr / 2017 & 1 & 2.9 & 25.9 & 1.2 & & 13 & \\
\hline RQ20170209/006 & $2017 / 0112$ & 7 & Hollandse kustzone noord & HOLLSKZNND & 18 / apr / 2017 & 1 & 2.2 & 23.7 & 0.8 & & 14 & \\
\hline RQ20170209/006 & $2017 / 0113$ & 8 & Hollandse kustzone noord & HOLLSKZNND & 18 / apr / 2017 & 1 & 2.4 & 24.9 & 0.8 & & 12 & \\
\hline RQ20170209/006 & $2017 / 0114$ & 9 & Hollandse kustzone noord & HOLLSKZNND & 18 / apr / 2017 & 2 & 3.3 & 28 & 1 & 0 & & 0 \\
\hline RQ20170209/006 & $2017 / 0115$ & 10 & Hollandse kustzone noord & HOLLSKZNND & 18 / apr / 2017 & 2 & 3.5 & 28.2 & 1 & 0 & & 0 \\
\hline RQ20170209/006 & $2017 / 0116$ & 11 & Hollandse kustzone noord & HOLLSKZNND & 18 / apr / 2017 & 2 & 3.3 & 27.7 & 1.4 & 0 & & 0 \\
\hline RQ20170209/006 & $2017 / 0117$ & 12 & Hollandse kustzone noord & HOLLSKZNND & 18 / apr / 2017 & 2 & 3.3 & 28 & 1.2 & 0 & & 0 \\
\hline RQ20170209/006 & $2017 / 0118$ & 13 & Hollandse kustzone noord & HOLLSKZNND & 18 / apr / 2017 & 2 & 3.6 & 28.2 & 1.2 & 0 & & 0 \\
\hline RQ20170209/006 & $2017 / 0119$ & 14 & Hollandse kustzone noord & HOLLSKZNND & 18 / apr / 2017 & 1 & 3.3 & 37.3 & 1 & & 13 & \\
\hline RQ20170209/006 & $2017 / 0120$ & 15 & Hollandse kustzone noord & HOLLSKZNND & 18 / apr / 2017 & 2 & 2.6 & 26.2 & 1.1 & 0 & & 0 \\
\hline RQ20170209/006 & $2017 / 0121$ & 16 & Hollandse kustzone noord & HOLLSKZNND & 18 / apr / 2017 & 1 & 2.9 & 26.8 & 1.1 & & 14 & \\
\hline RQ20170209/006 & $2017 / 0122$ & 17 & Hollandse kustzone noord & HOLLSKZNND & 18 / apr / 2017 & 2 & 3.3 & 29.7 & 1.3 & 0 & & 0 \\
\hline RQ20170209/006 & $2017 / 0123$ & 18 & Hollandse kustzone noord & HOLLSKZNND & 18 / apr / 2017 & 2 & 2.5 & 25.2 & 1 & 0 & & 0 \\
\hline RQ20170209/006 & $2017 / 0124$ & 19 & Hollandse kustzone noord & HOLLSKZNND & 18 / apr / 2017 & 1 & 1.8 & 22.7 & 0.7 & & 12 & \\
\hline RQ20170209/006 & $2017 / 0125$ & 20 & Hollandse kustzone noord & HOLLSKZNND & 18 / apr / 2017 & 1 & 1.8 & 22.6 & 0.7 & & 13.5 & \\
\hline RQ20170209/006 & $2017 / 0126$ & 21 & Hollandse kustzone noord & HOLLSKZNND & 18 / apr / 2017 & 2 & 3.7 & 29.4 & 1.3 & 0 & & 0 \\
\hline RQ20170209/006 & $2017 / 0127$ & 22 & Hollandse kustzone noord & HOLLSKZNND & 18 / apr / 2017 & 2 & 4.1 & 30 & 1.3 & 0 & & 0 \\
\hline RQ20170209/006 & $2017 / 0128$ & 23 & Hollandse kustzone noord & HOLLSKZNND & 18 / apr / 2017 & 2 & 3.2 & 27.4 & 1.2 & 0 & & 0 \\
\hline RQ20170209/006 & $2017 / 0129$ & 24 & Hollandse kustzone noord & HOLLSKZNND & 18 / apr / 2017 & 1 & 2.9 & 26.9 & 1.2 & & 14 & \\
\hline RQ20170209/006 & $2017 / 0130$ & 25 & Hollandse kustzone noord & HOLLSKZNND & 18 / apr / 2017 & 1 & 2.8 & 27.1 & 1.1 & & 15 & \\
\hline RQ20170209/006 & $2017 / 0131$ & 26 & Hollandse kustzone noord & HOLLSKZNND & 18 / apr / 2017 & 2 & 3.5 & 28 & 1.2 & 0 & & 0 \\
\hline RQ20170209/006 & $2017 / 0132$ & 27 & Hollandse kustzone noord & HOLLSKZNND & 18 / apr / 2017 & 2 & 2.7 & 26.2 & 0.9 & 0 & & 0 \\
\hline RQ20170209/006 & $2017 / 0133$ & 28 & Hollandse kustzone noord & HOLLSKZNND & 18 / apr / 2017 & 1 & 2.0 & 23.5 & 0.9 & & 13 & \\
\hline RQ20170209/006 & $2017 / 0134$ & 29 & Hollandse kustzone noord & HOLLSKZNND & 18 / apr / 2017 & 1 & 2.2 & 24.8 & 1 & & 12 & \\
\hline RQ20170209/006 & $2017 / 0135$ & 30 & Hollandse kustzone noord & HOLLSKZNND & 18 / apr / 2017 & 2 & 4.1 & 29.4 & 1.4 & 0 & & 0 \\
\hline RQ20170209/006 & $2017 / 0136$ & 31 & Hollandse kustzone noord & HOLLSKZNND & 18 / apr / 2017 & 2 & 3.1 & 26.4 & 1.2 & 0 & & 0 \\
\hline RQ20170209/006 & $2017 / 0137$ & 32 & Hollandse kustzone noord & HOLLSKZNND & 18 / apr / 2017 & 1 & 2.6 & 26.8 & 0.8 & & 12.5 & \\
\hline RQ20170209/006 & $2017 / 0138$ & 33 & Hollandse kustzone noord & HOLLSKZNND & 18 / apr / 2017 & 2 & 2.9 & 27.2 & 1.2 & 0 & & 0 \\
\hline RQ20170209/006 & $2017 / 0139$ & 34 & Hollandse kustzone noord & HOLLSKZNND & 18 / apr / 2017 & 1 & 2.4 & 26 & 0.9 & & 11 & \\
\hline RQ20170209/006 & $2017 / 0140$ & 35 & Hollandse kustzone noord & HOLLSKZNND & 18 / apr / 2017 & 2 & 3.1 & 26.5 & 1.4 & 0 & & 0 \\
\hline RQ20170209/006 & $2017 / 0141$ & 36 & Hollandse kustzone noord & HOLLSKZNND & 18 / apr / 2017 & 2 & 3.4 & 27.6 & 1.4 & 0 & & 0 \\
\hline RQ20170209/006 & $2017 / 0142$ & 37 & Hollandse kustzone noord & HOLLSKZNND & 18 / apr / 2017 & 1 & 2.8 & 25.7 & 1 & & 14 & \\
\hline RQ20170209/006 & $2017 / 0143$ & 38 & Hollandse kustzone noord & HOLLSKZNND & 18 / apr / 2017 & 1 & 2.8 & 26.4 & 0.9 & & 15 & \\
\hline RQ20170209/006 & $2017 / 0144$ & 39 & Hollandse kustzone noord & HOLLSKZNND & 18 / apr / 2017 & 1 & 2.4 & 26.0 & 0.9 & & 14 & \\
\hline RQ20170209/006 & $2017 / 0145$ & 40 & Hollandse kustzone noord & HOLLSKZNND & 18 / apr / 2017 & 1 & 2.9 & 26.0 & 0.9 & & 14 & \\
\hline
\end{tabular}




\begin{tabular}{|c|c|c|c|c|c|c|c|c|c|c|c|c|}
\hline Requestnummer & $\begin{array}{l}\text { Monster } \\
\text { nummer }\end{array}$ & $\mathrm{Nr}$. & Locatie & $\begin{array}{l}\text { DONAR } \\
\text { locatie }\end{array}$ & $\begin{array}{c}\text { Bemonster } \\
\text { datum }\end{array}$ & $\begin{array}{c}\text { Geslac } \\
h t \\
M=1, \\
V=2, \\
p=3\end{array}$ & $\begin{array}{c}\text { Totale } \\
\text { gewicht } \\
(\mathrm{g}-1 \mathrm{dec})\end{array}$ & $\begin{array}{l}\begin{array}{l}\text { Lengte } \\
\text { schelp } \\
\text { (mm - } \\
1 \mathrm{dec})\end{array}\end{array}$ & $\begin{array}{c}\text { Gewicht } \\
\text { vlees } \\
(\mathrm{g}-1 \mathrm{dec})\end{array}$ & \begin{tabular}{|c|} 
Penislengt \\
$\mathrm{e}$ \\
vrouw \\
$(\mathrm{mm}-$ \\
$1 \mathrm{dec})$
\end{tabular} & \begin{tabular}{|c|} 
Penislengt \\
e \\
man \\
$(\mathrm{mm}-$ \\
$1 \mathrm{dec})$
\end{tabular} & $\begin{array}{c}\text { Stadium } \\
0,1,2,3 \\
\text { a,b,c }\end{array}$ \\
\hline RQ20170209/007 & $2017 / 0147$ & 1 & Hollandse kustzone midden & HOLLSKZNMDN & 29 / mrt / 2017 & 2 & 2.9 & 27.5 & 1.1 & 0 & & 0 \\
\hline RQ20170209/007 & $2017 / 0148$ & 2 & Hollandse kustzone midden & HOLLSKZNMDN & 29 / mrt / 2017 & 2 & 2.4 & 26.2 & 0.8 & 0 & & 0 \\
\hline RQ20170209/007 & $2017 / 0149$ & 3 & Hollandse kustzone midden & HOLLSKZNMDN & 29 / mrt / 2017 & 2 & 2.7 & 26.2 & 1.2 & 0 & & 0 \\
\hline RQ20170209/007 & $2017 / 0150$ & 4 & Hollandse kustzone midden & HOLLSKZNMDN & 29 / mrt / 2017 & 2 & 2.8 & 27.2 & 1.2 & 0 & & 0 \\
\hline RQ20170209/007 & $2017 / 0151$ & 5 & Hollandse kustzone midden & HOLLSKZNMDN & 29 / mrt / 2017 & 2 & 2.7 & 26 & 1.1 & 0 & & 0 \\
\hline RQ20170209/007 & $2017 / 0152$ & 6 & Hollandse kustzone midden & HOLLSKZNMDN & 29 / mrt / 2017 & 1 & 2.9 & 27.2 & 1.3 & & 9.5 & \\
\hline RQ20170209/007 & $2017 / 0153$ & 7 & Hollandse kustzone midden & HOLLSKZNMDN & 29 / mrt / 2017 & 1 & 3 & 28.8 & 1.4 & & 9.0 & \\
\hline RQ20170209/007 & $2017 / 0154$ & 8 & Hollandse kustzone midden & HOLLSKZNMDN & 29 / mrt / 2017 & 2 & 2 & 23.8 & 0.9 & 0 & & 0 \\
\hline RQ20170209/007 & $2017 / 0155$ & 9 & Hollandse kustzone midden & HOLLSKZNMDN & 29 / mrt / 2017 & 2 & 3.4 & 27.9 & 1.2 & 0 & & 0 \\
\hline RQ20170209/007 & $2017 / 0156$ & 10 & Hollandse kustzone midden & HOLLSKZNMDN & 29 / mrt / 2017 & 2 & 2.9 & 27.4 & 1.1 & 0 & & 0 \\
\hline RQ20170209/007 & $2017 / 0157$ & 11 & Hollandse kustzone midden & HOLLSKZNMDN & 29 / mrt / 2017 & 1 & 2.6 & 26.1 & 1 & & 13.0 & \\
\hline RQ20170209/007 & $2017 / 0158$ & 12 & Hollandse kustzone midden & HOLLSKZNMDN & 29 / mrt / 2017 & 1 & 2.5 & 24.2 & 0.8 & & 10.5 & \\
\hline RQ20170209/007 & $2017 / 0159$ & 13 & Hollandse kustzone midden & HOLLSKZNMDN & 29 / mrt / 2017 & 2 & 3.2 & 27.6 & 1.2 & 0 & & 0 \\
\hline RQ20170209/007 & $2017 / 0160$ & 14 & Hollandse kustzone midden & HOLLSKZNMDN & 29 / mrt / 2017 & 1 & 2.6 & 25.5 & 0.9 & & 12.0 & \\
\hline RQ20170209/007 & $2017 / 0161$ & 15 & Hollandse kustzone midden & HOLLSKZNMDN & 29 / mrt / 2017 & 2 & 3.4 & 27.5 & 1 & 0 & & 0 \\
\hline RQ20170209/007 & $2017 / 0162$ & 16 & Hollandse kustzone midden & HOLLSKZNMDN & 29 / mrt / 2017 & 1 & 2.7 & 25.3 & 1.5 & & 12.5 & \\
\hline RQ20170209/007 & $2017 / 0163$ & 17 & Hollandse kustzone midden & HOLLSKZNMDN & 29 / mrt / 2017 & 1 & 3.1 & 26.8 & 0.9 & & 10.3 & \\
\hline RQ20170209/007 & $2017 / 0164$ & 18 & Hollandse kustzone midden & HOLLSKZNMDN & 29 / mrt / 2017 & 1 & 2.3 & 25.8 & 0.8 & & 12.0 & \\
\hline RQ20170209/007 & $2017 / 0165$ & 19 & Hollandse kustzone midden & HOLLSKZNMDN & 29 / mrt / 2017 & 2 & 2.7 & 25.8 & 1 & 0 & & 0 \\
\hline RQ20170209/007 & $2017 / 0166$ & 20 & Hollandse kustzone midden & HOLLSKZNMDN & 29 / mrt / 2017 & 1 & 2.3 & 24.3 & 0.9 & & 10.0 & \\
\hline RQ20170209/007 & $2017 / 0167$ & 21 & Hollandse kustzone midden & HOLLSKZNMDN & 29 / mrt / 2017 & 2 & 3.0 & 27.0 & 0.9 & 0 & & 0 \\
\hline RQ20170209/007 & $2017 / 0168$ & 22 & Hollandse kustzone midden & HOLLSKZNMDN & 29 / mrt / 2017 & 2 & 3.2 & 28.5 & 1.3 & 0 & & 0 \\
\hline RQ20170209/007 & $2017 / 0169$ & 23 & Hollandse kustzone midden & HOLLSKZNMDN & 29 / mrt / 2017 & 1 & 2.6 & 25.8 & 0.6 & & 8.0 & \\
\hline RQ20170209/007 & $2017 / 0170$ & 24 & Hollandse kustzone midden & HOLLSKZNMDN & 29 / mrt / 2017 & 1 & 3.1 & 28.1 & 1.3 & & 13.0 & \\
\hline RQ20170209/007 & $2017 / 0171$ & 25 & Hollandse kustzone midden & HOLLSKZNMDN & 29 / mrt / 2017 & 2 & 2.8 & 27.5 & 1.2 & 0 & & 0 \\
\hline RQ20170209/007 & $2017 / 0172$ & 26 & Hollandse kustzone midden & HOLLSKZNMDN & 29 / mrt / 2017 & 2 & 3.3 & 28 & 1.1 & 0 & & 0 \\
\hline RQ20170209/007 & $2017 / 0173$ & 27 & Hollandse kustzone midden & HOLLSKZNMDN & 29 / mrt / 2017 & 1 & 2 & 23.8 & 0.9 & & 12.0 & \\
\hline RQ20170209/007 & $2017 / 0174$ & 28 & Hollandse kustzone midden & HOLLSKZNMDN & 29 / mrt / 2017 & 2 & 3.8 & 29.4 & 1.3 & 0 & & 0 \\
\hline RQ20170209/007 & $2017 / 0175$ & 29 & Hollandse kustzone midden & HOLLSKZNMDN & 29 / mrt / 2017 & 2 & 3.3 & 28.2 & 1.3 & 0 & & 0 \\
\hline RQ20170209/007 & $2017 / 0176$ & 30 & Hollandse kustzone midden & HOLLSKZNMDN & 29 / mrt / 2017 & 2 & 2.6 & 25.7 & 0.9 & 0 & & 0 \\
\hline RQ20170209/007 & $2017 / 0177$ & 31 & Hollandse kustzone midden & HOLLSKZNMDN & 29 / mrt / 2017 & 2 & 3.5 & 27.8 & 1 & 0 & & 0 \\
\hline RQ20170209/007 & $2017 / 0178$ & 32 & Hollandse kustzone midden & HOLLSKZNMDN & 29 / mrt / 2017 & 2 & 2.6 & 25.4 & 1.2 & 0 & & 0 \\
\hline RQ20170209/007 & $2017 / 0179$ & 33 & Hollandse kustzone midden & HOLLSKZNMDN & 29 / mrt / 2017 & 1 & 2.8 & 26 & 1 & & 11.5 & \\
\hline RQ20170209/007 & $2017 / 0180$ & 34 & Hollandse kustzone midden & HOLLSKZNMDN & 29 / mrt / 2017 & 2 & 2.7 & 25.8 & 1 & 0 & & 0 \\
\hline RQ20170209/007 & $2017 / 0181$ & 35 & Hollandse kustzone midden & HOLLSKZNMDN & 29 / mrt / 2017 & 2 & 3 & 26.4 & 1.2 & 0 & & 0 \\
\hline RQ20170209/007 & $2017 / 0182$ & 36 & Hollandse kustzone midden & HOLLSKZNMDN & 29 / mrt / 2017 & 2 & 3 & 27.8 & 1.4 & 0 & & 0 \\
\hline RQ20170209/007 & $2017 / 0183$ & 37 & Hollandse kustzone midden & HOLLSKZNMDN & 29 / mrt / 2017 & 2 & 3.5 & 26.7 & 1.2 & 0 & & 0 \\
\hline RQ20170209/007 & $2017 / 0184$ & 38 & Hollandse kustzone midden & HOLLSKZNMDN & 29 / mrt / 2017 & 1 & 2.5 & 24.8 & 0.8 & & 10.5 & \\
\hline RQ20170209/007 & $2017 / 0185$ & 39 & Hollandse kustzone midden & HOLLSKZNMDN & 29 / mrt / 2017 & 2 & 3.1 & 27.1 & 1.2 & 0 & & 0 \\
\hline RQ20170209/007 & $2017 / 0186$ & 40 & Hollandse kustzone midden & HOLLSKZNMDN & 29 / mrt / 2017 & 2 & 2.6 & 25.6 & 1 & 0 & & 0 \\
\hline
\end{tabular}




\begin{tabular}{|c|c|c|c|c|c|c|c|c|c|c|c|c|}
\hline Requestnummer & $\begin{array}{l}\text { Monster } \\
\text { nummer }\end{array}$ & Nr. & Locatie & $\begin{array}{l}\text { DONAR } \\
\text { locatie }\end{array}$ & $\begin{array}{c}\text { Bemonster } \\
\text { datum }\end{array}$ & $\begin{array}{c}\text { Geslac } \\
\text { ht } \\
M=1, \\
V=2, \\
p=3\end{array}$ & \begin{tabular}{|c|} 
Totale \\
gewicht \\
$(\mathrm{g}-1 \mathrm{dec})$
\end{tabular} & $\begin{array}{l}\text { Lengte } \\
\text { schelp } \\
(\mathrm{mm}- \\
1 \mathrm{dec})\end{array}$ & $\begin{array}{c}\text { Gewicht } \\
\text { vlees } \\
(\mathrm{g}-1 \mathrm{dec})\end{array}$ & \begin{tabular}{|c|} 
Penislengt \\
$\mathrm{e}$ \\
vrouw \\
$(\mathrm{mm}-$ \\
$1 \mathrm{dec})$
\end{tabular} & \begin{tabular}{|c|} 
Penislengt \\
$\mathrm{e}$ \\
man \\
$(\mathrm{mm}-$ \\
$1 \mathrm{dec})$ \\
\end{tabular} & $\begin{array}{c}\text { Stadium } \\
0,1,2,3 \\
\text { a,b,c }\end{array}$ \\
\hline RQ20170209/008 & $2017 / 0188$ & 1 & Hollandse kustzone zuid & HOLLSKZNZD & 10 / apr / 2017 & 2 & 3.2 & 28.4 & 1.2 & 0 & & 0 \\
\hline RQ20170209/008 & $2017 / 0189$ & 2 & Hollandse kustzone zuid & HOLLSKZNZD & 10 / apr / 2017 & 1 & 2.8 & 27.0 & 1.3 & & 15 & \\
\hline RQ20170209/008 & $2017 / 0190$ & 3 & Hollandse kustzone zuid & HOLLSKZNZD & 10 / apr / 2017 & 1 & 2.5 & 26.1 & 1.2 & & 16 & \\
\hline RQ20170209/008 & $2017 / 0191$ & 4 & Hollandse kustzone zuid & HOLLSKZNZD & 10 / apr / 2017 & 2 & 2.7 & 26.8 & 1.3 & 0 & & 0 \\
\hline RQ20170209/008 & $2017 / 0192$ & 5 & Hollandse kustzone zuid & HOLLSKZNZD & 10 / apr / 2017 & 2 & 2.8 & 26.6 & 1.2 & 0 & & 0 \\
\hline RQ20170209/008 & $2017 / 0193$ & 6 & Hollandse kustzone zuid & HOLLSKZNZD & 10 / apr / 2017 & 2 & 2.6 & 27.3 & 1.2 & 0 & & 0 \\
\hline RQ20170209/008 & $2017 / 0194$ & 7 & Hollandse kustzone zuid & HOLLSKZNZD & 10 / apr / 2017 & 1 & 3.3 & 28.5 & 1.3 & & 15.5 & \\
\hline RQ20170209/008 & $2017 / 0195$ & 8 & Hollandse kustzone zuid & HOLLSKZNZD & 10 / apr / 2017 & 1 & 3.7 & 25 & 1.1 & & 15 & \\
\hline RQ20170209/008 & $2017 / 0196$ & 9 & Hollandse kustzone zuid & HOLLSKZNZD & 10 / apr / 2017 & 2 & 3.0 & 27.5 & 1.3 & 0 & & 0 \\
\hline RQ20170209/008 & $2017 / 0197$ & 10 & Hollandse kustzone zuid & HOLLSKZNZD & 10 / apr / 2017 & 1 & 2.7 & 26 & 1.1 & & 16 & \\
\hline RQ20170209/008 & $2017 / 0198$ & 11 & Hollandse kustzone zuid & HOLLSKZNZD & 10 / apr / 2017 & 1 & 2.6 & 25.8 & 1 & & 15 & \\
\hline RQ20170209/008 & $2017 / 0199$ & 12 & Hollandse kustzone zuid & HOLLSKZNZD & 10 / apr / 2017 & 2 & 2.3 & 24.9 & 1 & 0 & & 0 \\
\hline RQ20170209/008 & $2017 / 0200$ & 13 & Hollandse kustzone zuid & HOLLSKZNZD & 10 / apr / 2017 & 2 & 3.0 & 26.5 & 1.1 & 0 & & 0 \\
\hline RQ20170209/008 & $2017 / 0201$ & 14 & Hollandse kustzone zuid & HOLLSKZNZD & 10 / apr / 2017 & 2 & 2.6 & 27.1 & 1.3 & 0 & & 0 \\
\hline RQ20170209/008 & $2017 / 0202$ & 15 & Hollandse kustzone zuid & HOLLSKZNZD & 10 / apr / 2017 & 2 & 2.7 & 26.5 & 1.1 & 0 & & 0 \\
\hline RQ20170209/008 & $2017 / 0203$ & 16 & Hollandse kustzone zuid & HOLLSKZNZD & 10 / apr / 2017 & 1 & 2.5 & 25.9 & 1 & & 14 & \\
\hline RQ20170209/008 & $2017 / 0204$ & 17 & Hollandse kustzone zuid & HOLLSKZNZD & 10 / apr / 2017 & 1 & 2.1 & 26.0 & 0.7 & & 13 & \\
\hline RQ20170209/008 & $2017 / 0205$ & 18 & Hollandse kustzone zuid & HOLLSKZNZD & 10 / apr / 2017 & 2 & 2.4 & 25.5 & 0.9 & 0 & & 0 \\
\hline RQ20170209/008 & $2017 / 0206$ & 19 & Hollandse kustzone zuid & HOLLSKZNZD & 10 / apr / 2017 & 1 & 2.5 & 26.1 & 1.1 & & 16 & \\
\hline RQ20170209/008 & $2017 / 0207$ & 20 & Hollandse kustzone zuid & HOLLSKZNZD & 10 / apr / 2017 & 1 & 2.7 & 27.2 & 1.2 & & 15 & \\
\hline RQ20170209/008 & $2017 / 0208$ & 21 & Hollandse kustzone zuid & HOLLSKZNZD & 10 / apr / 2017 & 1 & 2.8 & 27.5 & 1.2 & & 14 & \\
\hline RQ20170209/008 & $2017 / 0209$ & 22 & Hollandse kustzone zuid & HOLLSKZNZD & 10 / apr / 2017 & 1 & 2.4 & 25.8 & 0.9 & & 12 & \\
\hline RQ20170209/008 & $2017 / 0210$ & 23 & Hollandse kustzone zuid & HOLLSKZNZD & 10 / apr / 2017 & 2 & 1.9 & 24 & 0.7 & 0 & & 0 \\
\hline RQ20170209/008 & $2017 / 0211$ & 24 & Hollandse kustzone zuid & HOLLSKZNZD & 10 / apr / 2017 & 2 & 3.3 & 28.1 & 1.4 & 0 & & 0 \\
\hline RQ20170209/008 & $2017 / 0212$ & 25 & Hollandse kustzone zuid & HOLLSKZNZD & 10 / apr / 2017 & 1 & 2.0 & 22.9 & 0.6 & & 15.5 & \\
\hline RQ20170209/008 & $2017 / 0213$ & 26 & Hollandse kustzone zuid & HOLLSKZNZD & 10 / apr / 2017 & 2 & 3.1 & 27.7 & 1.1 & 0 & & 0 \\
\hline RQ20170209/008 & $2017 / 0214$ & 27 & Hollandse kustzone zuid & HOLLSKZNZD & 10 / apr / 2017 & 1 & 2.8 & 26.3 & 1.2 & & 15.5 & \\
\hline RQ20170209/008 & $2017 / 0215$ & 28 & Hollandse kustzone zuid & HOLLSKZNZD & 10 / apr / 2017 & 1 & 2.8 & 28.5 & 1.1 & & 15 & \\
\hline RQ20170209/008 & $2017 / 0216$ & 29 & Hollandse kustzone zuid & HOLLSKZNZD & 10 / apr / 2017 & 2 & 2.4 & 25 & 0.7 & 0 & & 0 \\
\hline RQ20170209/008 & $2017 / 0217$ & 30 & Hollandse kustzone zuid & HOLLSKZNZD & 10 / apr / 2017 & 1 & 2.9 & 26.5 & 1.1 & & 16 & \\
\hline RQ20170209/008 & $2017 / 0218$ & 31 & Hollandse kustzone zuid & HOLLSKZNZD & 10 / apr / 2017 & 2 & 3.4 & 28.5 & 1.3 & 0 & & 0 \\
\hline RQ20170209/008 & $2017 / 0219$ & 32 & Hollandse kustzone zuid & HOLLSKZNZD & 10 / apr / 2017 & 2 & 2.9 & 26.7 & 1.1 & 0 & & 0 \\
\hline RQ20170209/008 & $2017 / 0220$ & 33 & Hollandse kustzone zuid & HOLLSKZNZD & 10 / apr / 2017 & 2 & 2.7 & 25.0 & 1.1 & 0 & & 0 \\
\hline RQ20170209/008 & $2017 / 0221$ & 34 & Hollandse kustzone zuid & HOLLSKZNZD & 10 / apr / 2017 & 2 & 3.2 & 29 & 1.3 & 0 & & 0 \\
\hline RQ20170209/008 & $2017 / 0222$ & 35 & Hollandse kustzone zuid & HOLLSKZNZD & 10 / apr / 2017 & 2 & 2.7 & 27 & 1.1 & 0 & & 0 \\
\hline RQ20170209/008 & $2017 / 0223$ & 36 & Hollandse kustzone zuid & HOLLSKZNZD & 10 / apr / 2017 & 2 & 2.9 & 28.3 & 1.3 & 0 & & 0 \\
\hline RQ20170209/008 & $2017 / 0224$ & 37 & Hollandse kustzone zuid & HOLLSKZNZD & 10 / apr / 2017 & 1 & 2.6 & 27.1 & 0.9 & & 17.5 & \\
\hline RQ20170209/008 & $2017 / 0225$ & 38 & Hollandse kustzone zuid & HOLLSKZNZD & 10 / apr / 2017 & 2 & 3.1 & 27.7 & 1.2 & 0 & & 0 \\
\hline RQ20170209/008 & $2017 / 0226$ & 39 & Hollandse kustzone zuid & HOLLSKZNZD & 10 / apr / 2017 & 1 & 2.8 & 26.3 & 1 & & 13.5 & \\
\hline RQ20170209/008 & $2017 / 0227$ & 40 & Hollandse kustzone zuid & HOLLSKZNZD & 10 / apr / 2017 & 1 & 2.1 & 24.9 & 0.7 & & 11.5 & \\
\hline
\end{tabular}




\begin{tabular}{|c|c|c|c|c|c|c|c|c|c|c|c|c|}
\hline Requestnummer & $\begin{array}{l}\text { Monster } \\
\text { nummer }\end{array}$ & $\mathrm{Nr}$. & Locatie & $\begin{array}{c}\text { DONAR } \\
\text { locatie }\end{array}$ & $\begin{array}{c}\text { Bemonster } \\
\text { datum }\end{array}$ & $\begin{array}{c}\text { Geslac } \\
\mathrm{ht} \\
\mathrm{M}=1, \\
\mathrm{~V}=2, \\
\mathrm{p}=3\end{array}$ & $\begin{array}{c}\text { Totale } \\
\text { gewicht } \\
(\mathrm{g}-1 \mathrm{dec})\end{array}$ & $\begin{array}{l}\text { Lengte } \\
\text { schelp } \\
(\mathrm{mm}- \\
1 \mathrm{dec})\end{array}$ & $\begin{array}{c}\text { Gewicht } \\
\text { vlees } \\
(\mathrm{g}-1 \mathrm{dec})\end{array}$ & \begin{tabular}{|c|} 
Penislengt \\
e \\
vrouw \\
$(\mathrm{mm}-$ \\
$1 \mathrm{dec})$
\end{tabular} & $\begin{array}{c}\text { Penislengt } \\
\mathrm{e} \\
\mathrm{man} \\
(\mathrm{mm}- \\
1 \mathrm{dec}) \\
\end{array}$ & \begin{tabular}{|c|} 
Stadium \\
$0,1,2,3$ \\
a,b,c
\end{tabular} \\
\hline RQ20170209/009 & $2017 / 0229$ & 1 & Haringvliet kustzone & HARVKZNE & 12 / apr / 2017 & 2 & 2.7 & 25.4 & 1 & 0 & & 0 \\
\hline RQ20170209/009 & $2017 / 0230$ & 2 & Haringvliet kustzone & HARVKZNE & 12 / apr / 2017 & 1 & 2.9 & 27.9 & 1 & & 13.5 & \\
\hline RQ20170209/009 & $2017 / 0231$ & 3 & Haringvliet kustzone & HARVKZNE & 12 / apr / 2017 & 1 & 2.4 & 25.1 & 0.8 & & 14 & \\
\hline RQ20170209/009 & $2017 / 0232$ & 4 & Haringvliet kustzone & HARVKZNE & 12 / apr / 2017 & 2 & 3 & 26.3 & 1.2 & 0 & & 0 \\
\hline RQ20170209/009 & 2017/0233 & 5 & Haringvliet kustzone & HARVKZNE & 12 / apr / 2017 & 1 & 3 & 27.6 & 1.4 & & 13 & \\
\hline RQ20170209/009 & $2017 / 0234$ & 6 & Haringvliet kustzone & HARVKZNE & 12 / apr / 2017 & 1 & 2.4 & 26.2 & 0.9 & & 9 & \\
\hline RQ20170209/009 & $2017 / 0235$ & 7 & Haringvliet kustzone & HARVKZNE & 12 / apr / 2017 & 1 & 2.6 & 26.3 & 0.9 & & 12 & \\
\hline RQ20170209/009 & 2017/0236 & 8 & Haringvliet kustzone & HARVKZNE & 12 / apr / 2017 & 1 & 1.7 & 23 & 0.5 & & 11 & \\
\hline RQ20170209/009 & $2017 / 0237$ & 9 & Haringvliet kustzone & HARVKZNE & 12 / apr / 2017 & 1 & 2.5 & 24.1 & 1 & & 13.5 & \\
\hline RQ20170209/009 & $2017 / 0238$ & 10 & Haringvliet kustzone & HARVKZNE & 12 / apr / 2017 & 2 & 3 & 27 & 1 & 0 & & 0 \\
\hline RQ20170209/009 & $2017 / 0239$ & 11 & Haringvliet kustzone & HARVKZNE & 12 / apr / 2017 & 1 & 2.4 & 26.4 & 0.8 & & 12.5 & \\
\hline RQ20170209/009 & $2017 / 0240$ & 12 & Haringvliet kustzone & HARVKZNE & 12 / apr / 2017 & 2 & 2.7 & 26 & 0.9 & 0 & & 0 \\
\hline RQ20170209/009 & $2017 / 0241$ & 13 & Haringvliet kustzone & HARVKZNE & 12 / apr / 2017 & 1 & 2.4 & 26.2 & 1 & & 14 & \\
\hline RQ20170209/009 & $2017 / 0242$ & 14 & Haringvliet kustzone & HARVKZNE & 12 / apr / 2017 & 2 & 3.2 & 27.3 & 1.3 & 0 & & 0 \\
\hline RQ20170209/009 & $2017 / 0243$ & 15 & Haringvliet kustzone & HARVKZNE & 12 / apr / 2017 & 1 & 2.3 & 24.8 & 0.9 & & 15 & \\
\hline RQ20170209/009 & $2017 / 0244$ & 16 & Haringvliet kustzone & HARVKZNE & 12 / apr / 2017 & 1 & 2.1 & 24.7 & 0.7 & & 15 & \\
\hline RQ20170209/009 & $2017 / 0245$ & 17 & Haringvliet kustzone & HARVKZNE & 12 / apr / 2017 & 2 & 2.7 & 26.5 & 1.1 & 0 & & 0 \\
\hline RQ20170209/009 & $2017 / 0246$ & 18 & Haringvliet kustzone & HARVKZNE & 12 / apr / 2017 & 1 & 2.6 & 26.3 & 0.9 & & 12.5 & \\
\hline RQ20170209/009 & $2017 / 0247$ & 19 & Haringvliet kustzone & HARVKZNE & 12 / apr / 2017 & 2 & 2.6 & 26.2 & 1.1 & 0 & & 0 \\
\hline RQ20170209/009 & $2017 / 0248$ & 20 & Haringvliet kustzone & HARVKZNE & 12 / apr / 2017 & 2 & 2.2 & 24.6 & 1 & 0 & & 0 \\
\hline RQ20170209/009 & $2017 / 0249$ & 21 & Haringvliet kustzone & HARVKZNE & 12 / apr / 2017 & 1 & 2.1 & 24.1 & 0.8 & & 12.5 & \\
\hline RQ20170209/009 & $2017 / 0250$ & 22 & Haringvliet kustzone & HARVKZNE & 12 / apr / 2017 & 1 & 2.2 & 24.4 & 0.7 & & 15 & \\
\hline RQ20170209/009 & $2017 / 0251$ & 23 & Haringvliet kustzone & HARVKZNE & 12 / apr / 2017 & 1 & 2.4 & 26.2 & 0.8 & & 13 & \\
\hline RQ20170209/009 & $2017 / 0252$ & 24 & Haringvliet kustzone & HARVKZNE & 12 / apr / 2017 & 2 & 4.0 & 29.2 & 1.2 & 0 & & 0 \\
\hline RQ20170209/009 & $2017 / 0253$ & 25 & Haringvliet kustzone & HARVKZNE & 12 / apr / 2017 & 2 & 2.7 & 25.9 & 1.2 & 0 & & 0 \\
\hline RQ20170209/009 & $2017 / 0254$ & 26 & Haringvliet kustzone & HARVKZNE & 12 / apr / 2017 & 1 & 2.6 & 27.1 & 0.9 & & 15.5 & \\
\hline RQ20170209/009 & $2017 / 0255$ & 27 & Haringvliet kustzone & HARVKZNE & 12 / apr / 2017 & 2 & 2.5 & 24.9 & 1 & 0 & & 0 \\
\hline RQ20170209/009 & $2017 / 0256$ & 28 & Haringvliet kustzone & HARVKZNE & 12 / apr / 2017 & 1 & 2.0 & 24.2 & 0.7 & & 14 & \\
\hline RQ20170209/009 & $2017 / 0257$ & 29 & Haringvliet kustzone & HARVKZNE & 12 / apr / 2017 & 1 & 1.6 & 21.8 & 0.7 & & 11.5 & \\
\hline RQ20170209/009 & $2017 / 0258$ & 30 & Haringvliet kustzone & HARVKZNE & 12 / apr / 2017 & 1 & 2.2 & 25.8 & 0.7 & & 15 & \\
\hline RQ20170209/009 & $2017 / 0259$ & 31 & Haringvliet kustzone & HARVKZNE & 12 / apr / 2017 & 1 & 2.0 & 24.4 & 0.6 & & 11 & \\
\hline RQ20170209/009 & $2017 / 0260$ & 32 & Haringvliet kustzone & HARVKZNE & 12 / apr / 2017 & 2 & 3.2 & 28.8 & 1.3 & 0 & & 0 \\
\hline RQ20170209/009 & $2017 / 0261$ & 33 & Haringvliet kustzone & HARVKZNE & 12 / apr / 2017 & 1 & 1.7 & 23.4 & 0.7 & & 13.5 & \\
\hline RQ20170209/009 & $2017 / 0262$ & 34 & Haringvliet kustzone & HARVKZNE & 12 / apr / 2017 & 2 & 2.3 & 26.8 & 0.9 & 0 & & 0 \\
\hline RQ20170209/009 & 2017/0263 & 35 & Haringvliet kustzone & HARVKZNE & 12 / apr / 2017 & 2 & 2.8 & 27.1 & 1.3 & 0 & & 0 \\
\hline RQ20170209/009 & $2017 / 0264$ & 36 & Haringvliet kustzone & HARVKZNE & 12 / apr / 2017 & 2 & 2.2 & 25.8 & 0.9 & 0 & & 0 \\
\hline RQ20170209/009 & $2017 / 0265$ & 37 & Haringvliet kustzone & HARVKZNE & 12 / apr / 2017 & 1 & 2.6 & 26 & 1 & & 12.5 & \\
\hline RQ20170209/009 & $2017 / 0266$ & 38 & Haringvliet kustzone & HARVKZNE & 12 / apr / 2017 & 1 & 2.8 & 25.9 & 1.2 & & 13 & \\
\hline RQ20170209/009 & $2017 / 0267$ & 39 & Haringvliet kustzone & HARVKZNE & 12 / apr / 2017 & 1 & 2.4 & 25.6 & 0.7 & & 11 & \\
\hline RQ20170209/009 & $2017 / 0268$ & 40 & Haringvliet kustzone & HARVKZNE & 12 / apr / 2017 & 2 & 3.4 & 28.4 & 1.4 & 0 & & 0 \\
\hline
\end{tabular}


Bijlage 2.3: Resultaten individuele Purperslakken

\begin{tabular}{|c|c|c|c|c|c|c|c|c|c|c|c|c|c|}
\hline Requestnummer & $\begin{array}{l}\text { Monster } \\
\text { nummer }\end{array}$ & Nr. & Locatie & $\begin{array}{l}\text { DONAR } \\
\text { locatie }\end{array}$ & Bemonster datum & $\begin{array}{c}\text { Geslacht } \\
M=1, V=2, \\
p=3\end{array}$ & $\begin{array}{c}\text { Totale } \\
\text { gewicht } \\
(\mathrm{g}-1 \mathrm{dec})\end{array}$ & $\begin{array}{l}\text { Lengte schelp } \\
(\mathrm{mm}-1 \mathrm{dec})\end{array}$ & $\begin{array}{c}\text { Gewicht } \\
\text { vlees } \\
\text { (g-1dec) }\end{array}$ & $\begin{array}{c}\text { Penislengte } \\
\text { vrouw } \\
(\mathrm{mm}-1 \mathrm{dec})\end{array}$ & $\begin{array}{c}\text { Penislengte } \\
\text { man } \\
(\mathrm{mm}-1 \mathrm{dec})\end{array}$ & \multicolumn{2}{|c|}{$\begin{array}{c}\text { Stadium } \\
0,1,2,3 \\
\text { a,b,c }\end{array}$} \\
\hline RQ20170209/010 & $2017 / 0270$ & 1 & Grevelingen kustzone & GREVLGKZNE & 13 / mrt / 2017 & 1 & 7.1 & 34.1 & 1.2 & & 5.2 & & \\
\hline RQ20170209/010 & $2017 / 0271$ & 2 & Grevelingen kustzone & GREVLGKZNE & 13 / mrt / 2017 & 1 & 6.7 & 35.3 & 1.5 & & 5.7 & & \\
\hline RQ20170209/010 & $2017 / 0272$ & 3 & Grevelingen kustzone & GREVLGKZNE & 13 / mrt / 2017 & 1 & 4.5 & 30.8 & 1 & & 4.2 & & \\
\hline RQ20170209/010 & 2017/0273 & 4 & Grevelingen kustzone & GREVLGKZNE & 13 / mrt / 2017 & 1 & 5.5 & 28.5 & 1 & & 6.8 & & \\
\hline RQ20170209/010 & $2017 / 0274$ & 5 & Grevelingen kustzone & GREVLGKZNE & 13 / mrt / 2017 & 1 & 6.8 & 32.3 & 1 & & 5.6 & & \\
\hline RQ20170209/010 & $2017 / 0275$ & 6 & Grevelingen kustzone & GREVLGKZNE & 13 / mrt / 2017 & 1 & 4.5 & 29.1 & 0.7 & & 4.3 & & \\
\hline RQ20170209/010 & 2017/0276 & 7 & Grevelingen kustzone & GREVLGKZNE & 13 / mrt / 2017 & 1 & 5.7 & 29.4 & 1.6 & & 5.6 & & \\
\hline$R Q 20170209 / 010$ & $2017 / 0277$ & 8 & Grevelingen kustzone & GREVLGKZNE & 13 / mrt / 2017 & 1 & 5.6 & 30.7 & 0.9 & & 5.7 & & \\
\hline RQ20170209/010 & $2017 / 0278$ & 9 & Grevelingen kustzone & GREVLGKZNE & 13 / mrt / 2017 & 1 & 6.8 & 31.3 & 1 & & 4.7 & & \\
\hline RQ20170209/010 & $2017 / 0279$ & 10 & Grevelingen kustzone & GREVLGKZNE & 13 / mrt / 2017 & 2 & 5.9 & 31.9 & 1 & 0 & & 0 & \\
\hline RQ20170209/010 & 2017/0280 & 11 & Grevelingen kustzone & GREVLGKZNE & 13 / mrt / 2017 & 2 & 6.0 & 32.6 & 1.6 & 0 & & 1 & $\mathrm{c}$ \\
\hline RQ20170209/010 & 2017/0281 & 12 & Grevelingen kustzone & GREVLGKZNE & 13 / mrt / 2017 & 2 & 4.8 & 30.9 & 1.4 & 0 & & 1 & c \\
\hline RQ20170209/010 & 2017/0282 & 13 & Grevelingen kustzone & GREVLGKZNE & 13 / mrt / 2017 & 1 & 5.8 & 28.2 & 1 & & 5.2 & & \\
\hline RQ20170209/010 & 2017/0283 & 14 & Grevelingen kustzone & GREVLGKZNE & 13 / mrt / 2017 & 1 & 6.7 & 32.6 & 1 & & 4.8 & & \\
\hline RQ20170209/010 & $2017 / 0284$ & 15 & Grevelingen kustzone & GREVLGKZNE & $13 / \mathrm{mrt} / 2017$ & 1 & 5.4 & 30.4 & 1.2 & & 4.9 & & \\
\hline RQ20170209/010 & $2017 / 0285$ & 16 & Grevelingen kustzone & GREVLGKZNE & 13 / mrt / 2017 & 2 & 6.8 & 34.4 & 1.3 & 0 & & 0 & \\
\hline RQ20170209/010 & $2017 / 0286$ & 17 & Grevelingen kustzone & GREVLGKZNE & 13 / mrt / 2017 & 1 & 4.7 & 30.0 & 0.7 & & 5.0 & & \\
\hline RQ20170209/010 & $2017 / 0287$ & 18 & Grevelingen kustzone & GREVLGKZNE & 13 / mrt / 2017 & 2 & 7.2 & 32.0 & 2 & 0 & & 0 & \\
\hline RQ20170209/010 & $2017 / 0288$ & 19 & Grevelingen kustzone & GREVLGKZNE & 13 / mrt / 2017 & 2 & 4.5 & 30.4 & 1.1 & 0 & & 0 & \\
\hline RQ20170209/010 & $2017 / 0289$ & 20 & Grevelingen kustzone & GREVLGKZNE & 13 / mrt / 2017 & 2 & 4.5 & 29.9 & 0.9 & 0 & & 0 & \\
\hline RQ20170209/010 & $2017 / 0290$ & 21 & Grevelingen kustzone & GREVLGKZNE & 13 / mrt / 2017 & 2 & 5.4 & 32.2 & 1 & 0 & & 0 & \\
\hline RQ20170209/010 & 2017/0291 & 22 & Grevelingen kustzone & GREVLGKZNE & 13 / mrt / 2017 & 1 & 6.0 & 31.0 & 0.9 & & 5.0 & & \\
\hline RQ20170209/010 & 2017/0292 & 23 & Grevelingen kustzone & GREVLGKZNE & 13 / mrt / 2017 & 2 & 4.5 & 29.7 & 1.3 & 0 & & 0 & \\
\hline RQ20170209/010 & $2017 / 0293$ & 24 & Grevelingen kustzone & GREVLGKZNE & 13 / mrt / 2017 & 1 & 5.3 & 31.8 & 0.9 & & 4.9 & & \\
\hline RQ20170209/010 & $2017 / 0294$ & 25 & Grevelingen kustzone & GREVLGKZNE & 13 / mrt / 2017 & 1 & 4.6 & 30.0 & 1 & & 4.3 & & \\
\hline RQ20170209/010 & $2017 / 0295$ & 26 & Grevelingen kustzone & GREVLGKZNE & 13 / mrt / 2017 & 2 & 5.4 & 32.8 & 1.2 & 0 & & 0 & \\
\hline RQ20170209/010 & $2017 / 0296$ & 27 & Grevelingen kustzone & GREVLGKZNE & 13 / mrt / 2017 & 1 & 5.8 & 29.4 & 1 & & 5.3 & & \\
\hline RQ20170209/010 & $2017 / 0297$ & 28 & Grevelingen kustzone & GREVLGKZNE & 13 / mrt / 2017 & 1 & 5.0 & 29.8 & 0.9 & & 4.9 & & \\
\hline RQ20170209/010 & $2017 / 0298$ & 29 & Grevelingen kustzone & GREVLGKZNE & 13 / mrt / 2017 & 1 & 4.9 & 30.1 & 1 & & 5.2 & & \\
\hline RQ20170209/010 & $2017 / 0299$ & 30 & Grevelingen kustzone & GREVLGKZNE & $13 / \mathrm{mrt} / 2017$ & 1 & 4.1 & 27.9 & 0.8 & & 4.2 & & \\
\hline RQ20170209/010 & $2017 / 0300$ & 31 & Grevelingen kustzone & GREVLGKZNE & 13 / mrt / 2017 & 2 & 5.0 & 30.1 & 0.8 & 0 & & 0 & \\
\hline RQ20170209/010 & 2017/0301 & 32 & Grevelingen kustzone & GREVLGKZNE & 13 / mrt / 2017 & 1 & 6.0 & 31.1 & 0.9 & & 4.9 & & \\
\hline RQ20170209/010 & 2017/0302 & 33 & Grevelingen kustzone & GREVLGKZNE & 13 / mrt / 2017 & 1 & 5.4 & 30.9 & 0.9 & & 4.8 & & \\
\hline RQ20170209/010 & $2017 / 0303$ & 34 & Grevelingen kustzone & GREVLGKZNE & 13 / mrt / 2017 & 2 & 5.1 & 31.0 & 0.7 & 0 & & 0 & \\
\hline RQ20170209/010 & $2017 / 0304$ & 35 & Grevelingen kustzone & GREVLGKZNE & 13 / mrt / 2017 & 2 & 5.8 & 30.8 & 0.9 & 0 & & 0 & \\
\hline RQ20170209/010 & $2017 / 0305$ & 36 & Grevelingen kustzone & GREVLGKZNE & 13 / mrt / 2017 & 1 & 5.6 & 29.4 & 1.4 & & 4.9 & & \\
\hline RQ20170209/010 & $2017 / 0306$ & 37 & Grevelingen kustzone & GREVLGKZNE & 13 / mrt / 2017 & 2 & 4.3 & 27.0 & 0.9 & 0 & & 0 & \\
\hline RQ20170209/010 & 2017/0307 & 38 & Grevelingen kustzone & GREVLGKZNE & 13 / mrt / 2017 & 2 & 5.4 & 30.8 & 1.2 & 0 & & 0 & \\
\hline RQ20170209/010 & 2017/0308 & 39 & Grevelingen kustzone & GREVLGKZNE & 13 / mrt / 2017 & 1 & 6.2 & 30.3 & 1.1 & & 5.5 & & \\
\hline RQ20170209/010 & 2017/0309 & 40 & Grevelingen kustzone & GREVLGKZNE & 13 / mrt / 2017 & 1 & 4.9 & 31.1 & 0.9 & & 5.0 & & \\
\hline
\end{tabular}




\begin{tabular}{|c|c|c|c|c|c|c|c|c|c|c|c|c|c|}
\hline Requestnummer & $\begin{array}{l}\text { Monster } \\
\text { nummer }\end{array}$ & Nr. & Locatie & $\begin{array}{l}\text { DONAR } \\
\text { locatie }\end{array}$ & Bemonster datum & $\begin{array}{c}\text { Geslacht } \\
M=1, V=2, \\
p=3\end{array}$ & $\begin{array}{c}\text { Totale } \\
\text { gewicht } \\
(\mathrm{g}-1 \mathrm{dec})\end{array}$ & $\begin{array}{c}\text { Lengte schelp } \\
(\mathrm{mm}-1 \mathrm{dec})\end{array}$ & $\begin{array}{c}\text { Gewicht } \\
\text { vlees } \\
(\mathrm{g}-1 \mathrm{dec})\end{array}$ & $\begin{array}{l}\text { Penislengte } \\
\text { vrouw } \\
(\mathrm{mm}-1 \mathrm{dec})\end{array}$ & $\begin{array}{c}\text { Penislengte } \\
\text { man } \\
(\mathrm{mm}-1 \mathrm{dec})\end{array}$ & & $\begin{array}{l}\text { dium } \\
, 2,3 \\
\text { tc }\end{array}$ \\
\hline RQ20170209/011 & $2017 / 0311$ & 1 & Oosterschelde kustzone & OOSTSDKZNE & 13 / mrt / 2017 & 2 & 5.7 & 34.6 & 1.1 & 0 & & 0 & \\
\hline RQ20170209/011 & 2017/0312 & 2 & Oosterschelde kustzone & OOSTSDKZNE & 13 / mrt / 2017 & 2 & 5.4 & 31.5 & 1.1 & 0 & & 0 & \\
\hline RQ20170209/011 & $2017 / 0313$ & 3 & Oosterschelde kustzone & OOSTSDKZNE & 13 / mrt / 2017 & 1 & 5.6 & 32.2 & 1.2 & & 5.2 & & \\
\hline RQ20170209/011 & $2017 / 0314$ & 4 & Oosterschelde kustzone & OOSTSDKZNE & 13 / mrt / 2017 & 2 & 5.4 & 28.9 & 1.1 & 0 & & 0 & \\
\hline RQ20170209/011 & $2017 / 0315$ & 5 & Oosterschelde kustzone & OOSTSDKZNE & $13 / \mathrm{mrt} / 2017$ & 2 & 4.5 & 29.7 & 1 & 0 & & 0 & \\
\hline RQ20170209/011 & $2017 / 0316$ & 6 & Oosterschelde kustzone & OOSTSDKZNE & 13 / mrt / 2017 & 2 & 4.3 & 28.7 & 0.8 & 0 & & 0 & \\
\hline RQ20170209/011 & $2017 / 0317$ & 7 & Oosterschelde kustzone & OOSTSDKZNE & $13 / \mathrm{mrt} / 2017$ & 2 & 5.4 & 30.2 & 1 & 0 & & 0 & \\
\hline RQ20170209/011 & $2017 / 0318$ & 8 & Oosterschelde kustzone & OOSTSDKZNE & 13 / mrt / 2017 & 2 & 4.7 & 28.8 & 1 & 0 & & 0 & \\
\hline RQ20170209/011 & $2017 / 0319$ & 9 & Oosterschelde kustzone & OOSTSDKZNE & 13 / mrt / 2017 & 1 & 4.5 & 29.0 & 1 & & 3.0 & & \\
\hline RQ20170209/011 & $2017 / 0320$ & 10 & Oosterschelde kustzone & OOSTSDKZNE & 13 / mrt / 2017 & 2 & 4.0 & 28.1 & 0.9 & 0 & & 0 & \\
\hline RQ20170209/011 & $2017 / 0321$ & 11 & Oosterschelde kustzone & OOSTSDKZNE & 13 / mrt / 2017 & 2 & 4.4 & 29.1 & 0.9 & 0 & & 0 & \\
\hline RQ20170209/011 & $2017 / 0322$ & 12 & Oosterschelde kustzone & OOSTSDKZNE & 13 / mrt / 2017 & 1 & 3.6 & 26.4 & 0.5 & & 3.6 & & \\
\hline RQ20170209/011 & $2017 / 0323$ & 13 & Oosterschelde kustzone & OOSTSDKZNE & 13 / mrt / 2017 & 2 & 4.3 & 27.9 & 1 & 0 & & 0 & \\
\hline RQ20170209/011 & $2017 / 0324$ & 14 & Oosterschelde kustzone & OOSTSDKZNE & 13 / mrt / 2017 & 1 & 3.6 & 27.1 & 0.7 & & 4.1 & & \\
\hline RQ20170209/011 & $2017 / 0325$ & 15 & Oosterschelde kustzone & OOSTSDKZNE & 13 / mrt / 2017 & 2 & 3.2 & 26.4 & 0.8 & 0 & & 0 & \\
\hline RQ20170209/011 & $2017 / 0326$ & 16 & Oosterschelde kustzone & OOSTSDKZNE & 13 / mrt / 2017 & 2 & 3.7 & 27.2 & 0.7 & 0 & & 0 & \\
\hline RQ20170209/011 & $2017 / 0327$ & 17 & Oosterschelde kustzone & OOSTSDKZNE & 13 / mrt / 2017 & 1 & 3.5 & 28.0 & 0.8 & & 4.6 & & \\
\hline RQ20170209/011 & $2017 / 0328$ & 18 & Oosterschelde kustzone & OOSTSDKZNE & 13 / mrt / 2017 & 2 & 4.1 & 28.2 & 0.7 & 0 & & 0 & \\
\hline RQ20170209/011 & $2017 / 0329$ & 19 & Oosterschelde kustzone & OOSTSDKZNE & 13 / mrt / 2017 & 1 & 3.5 & 26.4 & 0.9 & & 4.5 & & \\
\hline$R Q 20170209 / 011$ & $2017 / 0330$ & 20 & Oosterschelde kustzone & OOSTSDKZNE & 13 / mrt / 2017 & 2 & 3.9 & 27.3 & 1 & 0 & & 0 & \\
\hline RQ20170209/011 & $2017 / 0331$ & 21 & Oosterschelde kustzone & OOSTSDKZNE & 13 / mrt / 2017 & 2 & 3.3 & 27.7 & 0.8 & 0 & & 0 & \\
\hline RQ20170209/011 & 2017/0332 & 22 & Oosterschelde kustzone & OOSTSDKZNE & 13 / mrt / 2017 & 1 & 3.7 & 26.9 & 0.6 & & 4.6 & & \\
\hline RQ20170209/011 & $2017 / 0333$ & 23 & Oosterschelde kustzone & OOSTSDKZNE & 13 / mrt / 2017 & 1 & 3.3 & 25.0 & 0.6 & & 3.6 & & \\
\hline RQ20170209/011 & $2017 / 0334$ & 24 & Oosterschelde kustzone & OOSTSDKZNE & 13 / mrt / 2017 & 2 & 3.4 & 27.3 & 0.6 & 0 & & 0 & \\
\hline RQ20170209/011 & $2017 / 0335$ & 25 & Oosterschelde kustzone & OOSTSDKZNE & 13 / mrt / 2017 & 1 & 3.4 & 26.7 & 0.7 & & 4.0 & & \\
\hline RQ20170209/011 & $2017 / 0336$ & 26 & Oosterschelde kustzone & OOSTSDKZNE & 13 / mrt / 2017 & 1 & 3.4 & 28.2 & 0.6 & & 3.5 & & \\
\hline$R Q 20170209 / 011$ & $2017 / 0337$ & 27 & Oosterschelde kustzone & OOSTSDKZNE & 13 / mrt / 2017 & 2 & 3.3 & 25.9 & 0.8 & 0 & & 0 & \\
\hline RQ20170209/011 & $2017 / 0338$ & 28 & Oosterschelde kustzone & OOSTSDKZNE & 13 / mrt / 2017 & 2 & 2.9 & 25.2 & 0.6 & 0 & & 0 & \\
\hline RQ20170209/011 & $2017 / 0339$ & 29 & Oosterschelde kustzone & OOSTSDKZNE & 13 / mrt / 2017 & 2 & 3.8 & 27.7 & 0.8 & 0 & & 0 & \\
\hline RQ20170209/011 & $2017 / 0340$ & 30 & Oosterschelde kustzone & OOSTSDKZNE & 13 / mrt / 2017 & 1 & 3.5 & 26.5 & 0.8 & & 4.2 & & \\
\hline RQ20170209/011 & $2017 / 0341$ & 31 & Oosterschelde kustzone & OOSTSDKZNE & 13 / mrt / 2017 & 2 & 3.3 & 26.0 & 0.7 & 0 & & 0 & \\
\hline RQ20170209/011 & $2017 / 0342$ & 32 & Oosterschelde kustzone & OOSTSDKZNE & 13 / mrt / 2017 & 1 & 3.3 & 25.4 & 0.6 & & 3.9 & & \\
\hline RQ20170209/011 & $2017 / 0343$ & 33 & Oosterschelde kustzone & OOSTSDKZNE & 13 / mrt / 2017 & 1 & 3.2 & 25.8 & 0.6 & & 4.0 & & \\
\hline RQ20170209/011 & $2017 / 0344$ & 34 & Oosterschelde kustzone & OOSTSDKZNE & 13 / mrt / 2017 & 1 & 3.1 & 26.1 & 0.6 & & 3.2 & & \\
\hline$R Q 20170209 / 011$ & $2017 / 0345$ & 35 & Oosterschelde kustzone & OOSTSDKZNE & 13 / mrt / 2017 & 2 & 3.1 & 26.3 & 0.8 & 0 & & 0 & \\
\hline RQ20170209/011 & $2017 / 0346$ & 36 & Oosterschelde kustzone & OOSTSDKZNE & 13 / mrt / 2017 & 1 & 3.1 & 26.6 & 0.6 & & 4.0 & & \\
\hline RQ20170209/011 & $2017 / 0347$ & 37 & Oosterschelde kustzone & OOSTSDKZNE & 13 / mrt / 2017 & 2 & 3.7 & 27.8 & 0.7 & 0 & & 0 & \\
\hline RQ20170209/011 & $2017 / 0348$ & 38 & Oosterschelde kustzone & OOSTSDKZNE & 13 / mrt / 2017 & 1 & 2.7 & 24.8 & 0.6 & & 4.0 & & \\
\hline RQ20170209/011 & $2017 / 0349$ & 39 & Oosterschelde kustzone & OOSTSDKZNE & 13 / mrt / 2017 & 1 & 3.6 & 26.6 & 0.6 & & 3.2 & & \\
\hline RQ20170209/011 & $2017 / 0350$ & 40 & Oosterschelde kustzone & OOSTSDKZNE & 13 / mrt / 2017 & 2 & 3.3 & 25.3 & 0.6 & 0 & & 0 & \\
\hline
\end{tabular}




\begin{tabular}{|c|c|c|c|c|c|c|c|c|c|c|c|c|c|}
\hline Requestnummer & $\begin{array}{l}\text { Monster } \\
\text { nummer }\end{array}$ & Nr. & Locatie & $\begin{array}{l}\text { DONAR } \\
\text { locatie }\end{array}$ & Bemonster datum & $\begin{array}{c}\text { Geslacht } \\
M=1, V=2, \\
p=3\end{array}$ & $\begin{array}{c}\text { Totale } \\
\text { gewicht } \\
\text { (g-1 dec) }\end{array}$ & $\begin{array}{l}\text { Lengte schelp } \\
(\mathrm{mm}-1 \mathrm{dec})\end{array}$ & $\begin{array}{c}\text { Gewicht } \\
\text { vlees } \\
(\mathrm{g}-1 \mathrm{dec})\end{array}$ & $\begin{array}{l}\text { Penislengte } \\
\text { vrouw } \\
(\mathrm{mm}-1 \mathrm{dec})\end{array}$ & $\begin{array}{c}\text { Penislengte } \\
\text { man } \\
(\mathrm{mm}-1 \mathrm{dec})\end{array}$ & $\begin{array}{r}\text { Stad } \\
0,1, \\
\text { et }\end{array}$ & $\begin{array}{l}\text { lium } \\
2,3 \\
\text { tc }\end{array}$ \\
\hline RQ20170209/012 & 2017/0352 & 1 & Westerschelde kustzone & WESTSDKZNE & 13 / mrt / 2017 & 2 & 7.3 & 34.1 & 1.3 & 0.5 & & 1 & $\mathrm{a}$ \\
\hline RQ20170209/012 & $2017 / 0353$ & 2 & Westerschelde kustzone & WESTSDKZNE & 13 / mrt / 2017 & 2 & 4.2 & 28.7 & 0.7 & 0.6 & & 1 & $\mathrm{a}$ \\
\hline RQ20170209/012 & $2017 / 0354$ & 3 & Westerschelde kustzone & WESTSDKZNE & $13 / \mathrm{mrt} / 2017$ & 2 & 3.1 & 26.6 & 0.6 & 0 & & 0 & \\
\hline RQ20170209/012 & $2017 / 0355$ & 4 & Westerschelde kustzone & WESTSDKZNE & $13 / \mathrm{mrt} / 2017$ & 1 & 6.5 & 30.9 & 0.9 & & 4.1 & & \\
\hline$R Q 20170209 / 012$ & 2017/0356 & 5 & Westerschelde kustzone & WESTSDKZNE & 13 / mrt / 2017 & 2 & 5.6 & 31.6 & 0.9 & 0 & & 0 & \\
\hline RQ20170209/012 & 2017/0357 & 6 & Westerschelde kustzone & WESTSDKZNE & 13 / mrt / 2017 & 2 & 4.3 & 27.0 & 0.7 & 0 & & 0 & \\
\hline RQ20170209/012 & $2017 / 0358$ & 7 & Westerschelde kustzone & WESTSDKZNE & 13 / mrt / 2017 & 2 & 3.2 & 25.7 & 0.6 & 0 & & 0 & \\
\hline RQ20170209/012 & $2017 / 0359$ & 8 & Westerschelde kustzone & WESTSDKZNE & $13 / \mathrm{mrt} / 2017$ & 2 & 5.2 & 28.2 & 0.8 & 0 & & 0 & \\
\hline RQ20170209/012 & $2017 / 0360$ & 9 & Westerschelde kustzone & WESTSDKZNE & 13 / mrt / 2017 & 1 & 5.1 & 31.0 & 0.8 & & 6.0 & & \\
\hline RQ20170209/012 & $2017 / 0361$ & 10 & Westerschelde kustzone & WESTSDKZNE & 13 / mrt / 2017 & 2 & 6.1 & 29.6 & 0.8 & 0 & & 0 & \\
\hline RQ20170209/012 & 2017/0362 & 11 & Westerschelde kustzone & WESTSDKZNE & 13 / mrt / 2017 & 1 & 5.4 & 28.8 & 1.1 & & 5.4 & & \\
\hline RQ20170209/012 & $2017 / 0363$ & 12 & Westerschelde kustzone & WESTSDKZNE & 13 / mrt / 2017 & 2 & 4.6 & 27.2 & 0.9 & 0 & & 0 & \\
\hline RQ20170209/012 & 2017/0364 & 13 & Westerschelde kustzone & WESTSDKZNE & 13 / mrt / 2017 & 1 & 3.5 & 28.2 & 0.8 & & 5.2 & & \\
\hline RQ20170209/012 & $2017 / 0365$ & 14 & Westerschelde kustzone & WESTSDKZNE & $13 / \mathrm{mrt} / 2017$ & 2 & 6.3 & 30.9 & 0.9 & 0 & & 0 & \\
\hline RQ20170209/012 & $2017 / 0366$ & 15 & Westerschelde kustzone & WESTSDKZNE & 13 / mrt / 2017 & 1 & 2.5 & 23.4 & 0.4 & & 4.3 & & \\
\hline RQ20170209/012 & $2017 / 0367$ & 16 & Westerschelde kustzone & WESTSDKZNE & $13 / \mathrm{mrt} / 2017$ & 2 & 3.0 & 24.3 & 0.5 & 0 & & 0 & \\
\hline RQ20170209/012 & $2017 / 0368$ & 17 & Westerschelde kustzone & WESTSDKZNE & $13 / \mathrm{mrt} / 2017$ & 2 & 5.1 & 31.0 & 1 & 0 & & 0 & \\
\hline RQ20170209/012 & $2017 / 0369$ & 18 & Westerschelde kustzone & WESTSDKZNE & 13 / mrt / 2017 & 2 & 3.3 & 27.8 & 0.6 & 0 & & 0 & \\
\hline RQ20170209/012 & $2017 / 0370$ & 19 & Westerschelde kustzone & WESTSDKZNE & 13 / mrt / 2017 & 1 & 6.8 & 31.6 & 0.8 & & 4.7 & & \\
\hline$R Q 20170209 / 012$ & $2017 / 0371$ & 20 & Westerschelde kustzone & WESTSDKZNE & $13 / \mathrm{mrt} / 2017$ & 2 & 4.3 & 28.1 & 0.5 & 0 & & 0 & \\
\hline RQ20170209/012 & $2017 / 0372$ & 21 & Westerschelde kustzone & WESTSDKZNE & 13 / mrt / 2017 & 2 & 6.5 & 28.8 & 1 & 0 & & 0 & \\
\hline RQ20170209/012 & $2017 / 0373$ & 22 & Westerschelde kustzone & WESTSDKZNE & 13 / mrt / 2017 & 2 & 5.7 & 29.7 & 1.2 & 0 & & 0 & \\
\hline RQ20170209/012 & $2017 / 0374$ & 23 & Westerschelde kustzone & WESTSDKZNE & $13 / \mathrm{mrt} / 2017$ & 1 & 6.2 & 31.4 & 0.8 & & 5.3 & & \\
\hline RQ20170209/012 & $2017 / 0375$ & 24 & Westerschelde kustzone & WESTSDKZNE & 13 / mrt / 2017 & 2 & 4.9 & 30.0 & 0.8 & 0 & & 0 & \\
\hline RQ20170209/012 & $2017 / 0376$ & 25 & Westerschelde kustzone & WESTSDKZNE & $13 / \mathrm{mrt} / 2017$ & 1 & 5.3 & 27.9 & 0.6 & & 3.9 & & \\
\hline RQ20170209/012 & $2017 / 0377$ & 26 & Westerschelde kustzone & WESTSDKZNE & 13 / mrt / 2017 & 1 & 5.1 & 29.0 & 0.7 & & 5.0 & & \\
\hline RQ20170209/012 & $2017 / 0378$ & 27 & Westerschelde kustzone & WESTSDKZNE & 13 / mrt / 2017 & 2 & 5.0 & 29.3 & 0.7 & 0 & & 0 & \\
\hline RQ20170209/012 & $2017 / 0379$ & 28 & Westerschelde kustzone & WESTSDKZNE & $13 / \mathrm{mrt} / 2017$ & 2 & 3.2 & 25.1 & 0.6 & 0 & & 0 & \\
\hline RQ20170209/012 & $2017 / 0380$ & 29 & Westerschelde kustzone & WESTSDKZNE & 13 / mrt / 2017 & 1 & 2.8 & 25.7 & 0.5 & & 3.2 & & \\
\hline RQ20170209/012 & $2017 / 0381$ & 30 & Westerschelde kustzone & WESTSDKZNE & $13 / \mathrm{mrt} / 2017$ & 1 & 2.6 & 24.3 & 0.5 & & 3.3 & & \\
\hline RQ20170209/012 & 2017/0382 & 31 & Westerschelde kustzone & WESTSDKZNE & 13 / mrt / 2017 & 1 & 2.9 & 25.2 & 0.5 & & 3.5 & & \\
\hline RQ20170209/012 & $2017 / 0383$ & 32 & Westerschelde kustzone & WESTSDKZNE & $13 / \mathrm{mrt} / 2017$ & 2 & 2.7 & 26.0 & 0.6 & 0 & & 0 & \\
\hline RQ20170209/012 & 2017/0384 & 33 & Westerschelde kustzone & WESTSDKZNE & 13 / mrt / 2017 & 1 & 2.9 & 25.3 & 0.5 & & 2.5 & & \\
\hline RQ20170209/012 & $2017 / 0385$ & 34 & Westerschelde kustzone & WESTSDKZNE & $13 / \mathrm{mrt} / 2017$ & 1 & 3.3 & 26.0 & 0.5 & & 3.1 & & \\
\hline RQ20170209/012 & 2017/0386 & 35 & Westerschelde kustzone & WESTSDKZNE & 13 / mrt / 2017 & 1 & 3.5 & 26.5 & 0.7 & & 3.3 & & \\
\hline RQ20170209/012 & $2017 / 0387$ & 36 & Westerschelde kustzone & WESTSDKZNE & $13 / \mathrm{mrt} / 2017$ & 1 & 4.6 & 26.9 & 0.5 & & 4.3 & & \\
\hline RQ20170209/012 & $2017 / 0388$ & 37 & Westerschelde kustzone & WESTSDKZNE & 13 / mrt / 2017 & 1 & 2.8 & 25.6 & 0.5 & & 3.2 & & \\
\hline RQ20170209/012 & 2017/0389 & 38 & Westerschelde kustzone & WESTSDKZNE & 13 / mrt / 2017 & 1 & 2.5 & 25.1 & 0.6 & & 3.5 & & \\
\hline RQ20170209/012 & $2017 / 0390$ & 39 & Westerschelde kustzone & WESTSDKZNE & 13 / mrt / 2017 & 2 & 3.5 & 26.6 & 0.6 & 0 & & 0 & \\
\hline RQ20170209/012 & 2017/0391 & 40 & Westerschelde kustzone & WESTSDKZNE & 13 / mrt / 2017 & 2 & 2.4 & 23.0 & 0.3 & 0 & & 0 & \\
\hline
\end{tabular}


Bijlage 3.1: Validatiegegevens analysemethoden

Resultaten referentiematerialen

\begin{tabular}{|c|c|c|c|c|c|c|c|c|c|}
\hline Groep & Component & Referentiemateriaal & $\begin{array}{l}\text { WMR-waarde } \\
\text { in } 2017\end{array}$ & $\underset{\text { in }}{\text { in }^{n}}$ & $\begin{array}{c}\text { WMR-waarde } \\
\text { QC-kaart }\end{array}$ & $\begin{array}{c}n \\
\text { totaal }\end{array}$ & $\begin{array}{c}\text { gecertificeerde } \\
\text { waarde }\end{array}$ & eenheid & kwalificatie \\
\hline . & Dry-weight & $\begin{array}{l}\text { IRM 2005/0775 } \\
\text { Haring/makreel }\end{array}$ & $69.93 \pm 0.29$ & 13 & $70.00 \pm 0.249$ & 268 & n.v.t. & $\%$ & goed \\
\hline Organotin & DBT kation & CRM Mossel CE-477 & $1353 \pm 266$ & 2 & $1391.8 \pm 162$ & 38 & $1540 \pm 120$ & $\mu \mathrm{g}$ kation $/ \mathrm{kg}$ & goed \\
\hline Organotin & MBT kation & CRM Mossel CE-477 & $1741 \pm 21$ & 2 & $1537 \pm 197$ & 38 & $1500 \pm 280$ & $\mu \mathrm{q}$ kation $/ \mathrm{kg}$ & goed \\
\hline Organotin & TBT kation & CRM Mossel CE-477 & $2285 \pm 401$ & 2 & $2176 \pm 220$ & 38 & $2200 \pm 190$ & $\mu \mathrm{g}$ kation $/ \mathrm{kg}$ & goed \\
\hline
\end{tabular}


Bijlage 3.2: Validatiegegevens analysemethoden

Resultaten Ringonderzoek Quasimeme in biota

labcode: Q127

\begin{tabular}{|l|c|c|c|c|c|c|c|c|c|c|}
\hline Group & Round & Period & Matrix & Group & Determinand & Unit & Z-score & Qualification & Comment & accreditatie \\
\hline BT1 & 2017.01 & apr 2017 & QTM112BT & - & Dry-weight & $\%$ & 0.0 & Satisfactory & Quasimeme & ja \\
\hline BT1 & 2017.01 & apr 2017 & QTM113BT & - & Dry-weight & $\%$ & -0.2 & Satisfactory & Quasimeme & ja \\
\hline BT1 & 2017.02 & nov 2017 & QTM114BT & - & Dry-weight & $\%$ & -0.3 & Satisfactory & Quasimeme & ja \\
\hline BT1 & 2017.02 & nov 2017 & QTM115BT & - & Dry-weight & $\%$ & -0.4 & Satisfactory & Quasimeme & ja \\
\hline BT8 & 2017.02 & nov 2017 & QSP062BT & Organotin & MBT & $\mu \mathrm{g} \mathrm{Sn} / \mathrm{kg}$ & 0.8 & Satisfactory & Quasimeme & nee \\
\hline BT8 & 2017.02 & nov 2017 & QSP063BT & Organotin & MBT & $\mu \mathrm{g} \mathrm{Sn} / \mathrm{kg}$ & -0.3 & Satisfactory & Quasimeme & nee \\
\hline BT8 & 2017.02 & nov 2017 & QSP062BT & Organotin & TBT & $\mu \mathrm{g} \mathrm{Sn} / \mathrm{kg}$ & 0.5 & Satisfactory & Quasimeme & ja \\
\hline BT8 & 2017.02 & nov 2017 & QSP063BT & Organotin & TBT & $\mu \mathrm{g} \mathrm{Sn} / \mathrm{kg}$ & 0.7 & Satisfactory & Quasimeme & ja \\
\hline
\end{tabular}


Bijlage 3.3: Validatiegegevens analysemethoden

Rapportagegrenzen en meetonzekerheid

\begin{tabular}{|l|l|c|c|c|c|c|c|}
\hline Groep & Component & $\begin{array}{c}\text { rapportage- } \\
\text { grens }\end{array}$ & $\begin{array}{c}\text { detectie- } \\
\text { limiet }\end{array}$ & eenheid & vc & $\mathbf{n}$ & $\boldsymbol{d}_{\mathbf{c}}$ \\
\hline- & Dry-weight & 0.3 & 0.15 & $\%$ & 3.5 & 50 & 0 \\
\hline Organotin & Monobutyltin & $<0.4$ & $<0.2$ & $\mu \mathrm{g} \mathrm{Sn} / \mathrm{kg}$ & 25.4 & 9 & 0 \\
\hline Organotin & Dibutyltin & $<0.3$ & $<0.2$ & $\mu \mathrm{g} \mathrm{Sn} / \mathrm{kg}$ & 14.7 & 19 & 0 \\
\hline Organotin & Tributyltin & $<0.3$ & $<0.2$ & $\mu \mathrm{g} \mathrm{Sn} / \mathrm{kg}$ & 24.6 & 9 & 0 \\
\hline Organotin & Monophenyltin & $<0.3$ & $<0.2$ & $\mu \mathrm{g} \mathrm{Sn} / \mathrm{kg}$ & 25.0 & & 0 \\
\hline Organotin & Diphenyltin & $<0.3$ & $<0.2$ & $\mu \mathrm{g} \mathrm{Sn} / \mathrm{kg}$ & 25.0 & & 0 \\
\hline Organotin & Triphenyltin & $<0.2$ & $<0.1$ & $\mu \mathrm{g} \mathrm{Sn} / \mathrm{kg}$ & 25.0 & & 0 \\
\hline Organotin & Monobutyltin kation & $<0.5$ & $<0.2$ & $\mu \mathrm{g} \mathrm{kation} / \mathrm{kg}$ & 25.4 & 9 & 0 \\
\hline Organotin & Dibutyltin kation & $<0.7$ & $<0.4$ & $\mu \mathrm{g} \mathrm{kation} / \mathrm{kg}$ & 14.7 & 19 & 0 \\
\hline Organotin & Tributyltin kation & $<0.7$ & $<0.4$ & $\mu \mathrm{g} \mathrm{kation} / \mathrm{kg}$ & 24.6 & 9 & 0 \\
\hline Organotin & Monophenyltin kation & $<0.6$ & $<0.3$ & $\mu \mathrm{g} \mathrm{kation} / \mathrm{kg}$ & 25.0 & & 0 \\
\hline Organotin & Diphenyltin kation & $<0.7$ & $<0.4$ & $\mu \mathrm{g} \mathrm{kation} / \mathrm{kg}$ & 25.0 & & 0 \\
\hline Organotin & Triphenyltin kation & $<0.8$ & $<0.4$ & $\mu \mathrm{g} \mathrm{kation} / \mathrm{kg}$ & 25.0 & & 0 \\
\hline
\end{tabular}

$\mathrm{n}=$ aantal ringonderzoeken aan de hand waarvan een Z-score bepaald kon worden

$d_{c}$ is de combined constant error in de eenheid van de concentratie van de component 